\title{
Exploratory Longitudinal, Spatial and Spatiotemporal Evaluation of the Raccoon Variant Rabies Virus in West Virginia, 2000- 2015
}

Kenneth. B Plants

Follow this and additional works at: https://researchrepository.wvu.edu/etd

\section{Recommended Citation}

Plants, Kenneth. B, "Exploratory Longitudinal, Spatial and Spatiotemporal Evaluation of the Raccoon Variant Rabies Virus in West Virginia, 2000- 2015" (2018). Graduate Theses, Dissertations, and Problem Reports. 7230.

https://researchrepository.wvu.edu/etd/7230

This Dissertation is protected by copyright and/or related rights. It has been brought to you by the The Research Repository @ WVU with permission from the rights-holder(s). You are free to use this Dissertation in any way that is permitted by the copyright and related rights legislation that applies to your use. For other uses you must obtain permission from the rights-holder(s) directly, unless additional rights are indicated by a Creative Commons license in the record and/ or on the work itself. This Dissertation has been accepted for inclusion in WVU Graduate Theses, Dissertations, and Problem Reports collection by an authorized administrator of The Research Repository @ WVU.

For more information, please contact researchrepository@mail.wvu.edu. 


\title{
Exploratory Longitudinal, Spatial and Spatiotemporal Evaluation of the Raccoon Variant Rabies Virus in West Virginia, 2000- 2015
}

\author{
Kenneth. B. Plants \\ Dissertation submitted \\ to the School of Public Health \\ at West Virginia University
}

In partial fulfillment of the requirements for the degree of

Doctor of Philosophy

In

Epidemiology

Sarah S. Knox, Ph.D., Committee Chair

Sijin Wen, Ph. D.

Thomas Hulsey, Ph. D.

Michael McCawley, Ph. D.

Brad Hillgartner, Ph. D.

Sheldon Owen, Ph. D.

Department of Epidemiology

Morgantown, West Virginia

2018

Keywords: Rabies, Spatiotemporal Analysis, Infectious Disease, West Virginia

Copyright 2018 Kenneth B. Plants 


\author{
ABSTRACT \\ Exploratory Longitudinal, Spatial and Spatiotemporal \\ Evaluation of the Raccoon Variant Rabies Virus in West \\ Virginia, 2000-2015
}

Kenneth B. Plants

Background and Objectives: Rabies is an almost invariably fatal viral disease of mammals. In West Virginia, there are two variants of the rabies virus, bat and raccoon. Raccoon rabies (RRV) was introduced subsequent to a release by hunters, and has since spread throughout the Northeastern United States and into Canada. There has been a notable lack of westward movement, however. The objectives of these studies are to 1) examine the behavior of RRV temporally during the study period 2) determine whether there are spatial determinants that may be associated with RRV incidence and 3) examine whether the change of spatial determinants with time over the study period can be correlated with changes in RRV incidence. Secondary objectives included evaluation of the oral rabies vaccine program, determination of whether clustering of disease occurred in the state, and examination of whether there were changes in RRV behavior in varying animal hosts.

Methods: County-level surveillance data were obtained from the West Virginia state health department and combined with geographic data from a number of publicly available databases. In the first study, RRV case numbers were examined to determine any trends over the study period, 2000 - 2015, and trends were compared for counties where oral rabies vaccination had occurred and those without vaccination program implementation, using negative binomial regression techniques and z-score comparisons. The second study evaluated several geospatial characteristics of the counties for association with disease incidence and clustering of disease, using Poisson spatial conditional autocorrelation regression within a Bayesian environment and local indicators of spatial autocorrelation. In the third study, integrated nested Laplace approximation (INLA) and negative binomial regression were utilized to allow simultaneous adjustment for the random effects of both time and space. In each study, analyses were performed for the data as a whole, in addition to analyses of various host subpopulations.

Results: Study 1. Analyses found statistically significant $(\mathrm{p} \leq 0.05)$ reductions in case numbers over the study period and showed that incidence rates were declining at significantly higher rates in counties where oral rabies vaccination had been deployed. Incidence showed significant declines for all animals in the study and the raccoon only subpopulation, but similar declines could not be shown in non-raccoon wildlife or domestic animals. Study 2. Statistically significant clustering of RRV cases was demonstrated for all host types examined, with clustering tending to occur in the eastern portion of the state and overlapping for the various host types. Several geospatial variables were shown to be significantly associated (credible intervals did not include 0 ) with RRV incidence, with several of the variables recurring among the host types. Study 3. Regression analyses that compensated for spatial and temporal autocorrelation showed that many of the variables found to be associated in study 2 did not retain those associations in univariate analyses, while multivariate analyses indicated that none of the variables that had changed over the study period were associated with RRV incidence. 
Conclusions: Across the three studies, differences were noted between the host types with regard to RRV behavior. It appears that reductions in RRV incidence for raccoons do not extend to the other host types. This is of particular concern in the case of domestic animals, as they represent the most likely source of human exposure. The oral rabies vaccine project does appear to be having an impact on RRV incidence. Spatial clustering of disease is occurring in all host types. Although there was some variation in significant determinants between the different hosts, as well as between the analytic approaches, geographic location and proximity to the Virginia border were most consistently present. In the multivariate INLA analyses, those variables that cannot be changed over time were the only ones of significance. The INLA approach was a substantial improvement over the more traditional methods and tended to corroborate the previous findings. The findings of these studies highlight the importance of using statistical methodologies that can accommodate the spatial and temporal structures embedded within public health surveillance data. 


\section{ACKNOWLEDGEMENTS}

I would like to thank the West Virginia University School of Public Health, Department of Epidemiology for the opportunity and support necessary for this project. Specifically, I would also like to thank Drs. Sarah Knox, Sijin Wen, Michael McCawley, Thomas Hulsey, Brad Hillgartner and Sheldon Owen for the time and effort they put forth to see the project to completion. Additionally, I would like to extend my appreciation to the West Virginia Department of Health and Human Resources, Bureau of Public Health for providing the data crucial to the project.

I am also grateful for the help and encouragement provided by my friends and colleagues, especially Dr. Brian Hendricks and the members of the 12-step recovery community of Morgantown. Without your help, it is unlikely I would have been able to complete the work in a timely manner, if at all.

Finally, I feel extreme gratitude for the love and support of my family, especially my wife Marti Keller and step-daughter Aubrey Keller. You took a huge leap of faith by uprooting and moving halfway across the country so that I might pursue my dream. Your patience and affection inspired me to see this through! 


\section{TABLE OF CONTENTS}

List of Tables

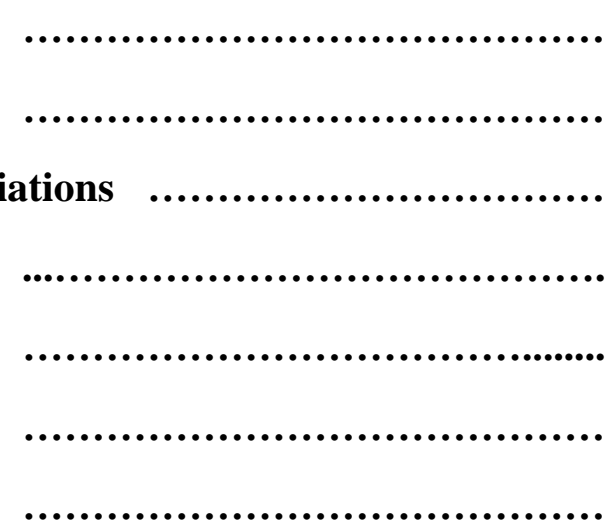

Chapter Three

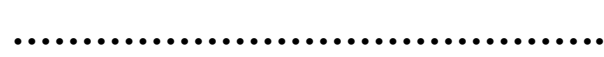

Project Conclusions

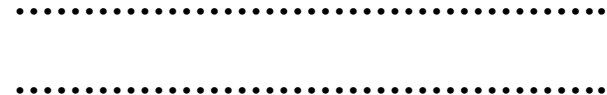

Literature Cited

Page vi

Page vii

Page viii

Pages 1 to 10

Pages 11 to 29

Pages 30 to 42

Pages 43 to 58

Pages 59 to 63

Pages 64 to 68 


\section{LIST OF TABLES}

Table 1.1: Counties contained within each of the zones, West Virginia.

Page 21

Table 1.2: Species breakdown of all non-raccoon wildlife and domestic animals infected with raccoon variant rabies virus, West Virginia, 2000-2015.

Page 23

Table 1.3: Comparison of negative binomial models fit for RRV in all hosts, West Virginia, 2000-2015.

Page 25

Table 1.4: Comparison of negative binomial models fit for RRV in the different animal types and zones, West Virginia, 2000-2015.

Page 26

Table 1.5: Results of z-score analyses comparing Zone 2 with Zone 3 for all hosts, West

Virginia, 2000-2015

Page 27

Table 2.1: Variables found by univariate Poisson regression to be significantly $(\alpha=0.05)$ associated with RRV infection by host type, West Virginia, 2000-2015.

Page 41

Table 3.1: Changes in value, among the WV counties with at least one RRV case, for the various covariates over the study period, 2000-2015.

Page 55

Table 3.2: Variables examined by univariate INLA negative binomial regression for association with RRV infection by host type, West Virginia, 2000-2015.

Page 56

Table 3.3: Final models from results of multivariate INLA analyses performed using negative binomial regression (using a log link function) for association with RRV infection by host type, West Virginia, 2000-2015.

Page 57 


\section{LIST OF FIGURES}

Figure 1.1: Map of the zones in West Virginia, as designated for this study Page 22

Figure 1.2: Numbers of raccoon variant rabies virus cases by animal type and year, West Virginia, 2000-2015.

Page 24

Figure 2.1: Total number of raccoon variant rabies virus (RRV) infected animal captures at the county level in West Virginia, 2000-2015.

Page 39

Figure 2.2: Local indicators of spatial autocorrelation maps for each of the host types examined, produced to investigate local clustering of raccoon variant rabies virus (RRV) at the county level in West Virginia, 2000-2015

Page 40

Figure 3.1: Map of West Virginia showing those counties with at least one RRV case during the study period

Page 54

Figure 4.1: Chart comparing the modelling techniques used in this project.

Page 62 


\title{
LIST OF NOMENCLATURE AND ABBREVIATIONS
}

\author{
Raccoon Variant Rabies Virus (RRV) \\ Integrated Nested Laplace Approximation (INLA) \\ Rhabdoviridae \\ Before Christian Era (BCE) \\ Centers for Disease Control and Prevention (CDC) \\ Post-exposure Prophylaxis (PEP) \\ Oral Rabies Vaccination (ORV) \\ Vulpes vulpes \\ Vulpes lagopus \\ Canis familiaris \\ Canis latrans \\ Vaccinia \\ Vector Encoding Rabies Glycoprotein \\ Mephitis mephitis \\ Procyon lotor \\ West Virginia (WV) \\ United States Department of Agriculture (USDA) \\ Animal and Plant Health Inspection Service (APHIS) \\ Cordon sanitaire \\ Nondomestic non-raccoons (NDNR) \\ Cross Species Transmission (CST) \\ Lynx rufous \\ Marmota monax \\ Castor canadensis \\ Didelphis virginiana \\ Lontra canadensis \\ Felis catus \\ Bos Taurus
}




\author{
Equus caballus \\ Capra aegragus hircus \\ Ovis aries \\ United States Geological Survey (USGS) \\ National Elevation Dataset (NED) \\ Digital Elevation Model (DEM) \\ National Land Cover Database (NLCD) \\ Urban Influence Codes (UIC) \\ Virginia (VA) \\ Local Indicators of Spatial Autocorrelation (LISA) \\ Federal Information Processing Standard (FIPS) \\ Conditional Autoregression (CAR) \\ Markov Chain Monte Carlo (MCMC) \\ North Carolina (NC)
}




\section{INTRODUCTION}

Almost invariably lethal, rabies infection can occur in any mammalian host. The virus responsible for the disease is rabies lyssavirus, found in the Rhabdoviridae family. The virus is highly neurotropic, resulting in a fatal encephalomyelitis. The earliest known written record of the disease is from the $23^{\text {rd }}$ century before the Christian era (BCE),${ }^{1}$ and a description of the means of transmission and pathogenesis of the disease is found in the writings of Democritus from the $5^{\text {th }}$ century BCE. ${ }^{2}$ The disease in the New World was primarily restricted to bats until the arrival of Europeans, after which genomic studies indicate canine rabies was introduced to an essentially immunologically naïve population of terrestrial mammals. ${ }^{3}$ In the interim, the disease has become enzootic throughout the Americas, with significant numbers of human deaths in Mexico, Central and South America.

Over the past 100 years, rabies in the United States has changed dramatically because of extensive vaccination efforts in domestic animals, especially dogs and cats. This strategy seems to have been successful. More than $90 \%$ of all animal cases reported annually to the Centers for Disease Control and Prevention (CDC) now occur in wildlife; whereas before 1960, the majority were in domestic animals. The principal rabies hosts in the U.S. today are wild mesocarnivores and bats. ${ }^{4}$ Most human exposures are from carnivores, and carnivore species most likely to be at risk varies regionally. Rabies kills thousands of people each year worldwide, but human deaths have become relatively rare in the United States. ${ }^{5,6}$

Affected wildlife animals, including raccoons, often lose their fear of humans and become active during daylight hours, drastically increasing their potential for increasing human and 
domestic animal exposures. When an animal bite is reported in humans, a dog or cat is immediately quarantined for an established observation period unless clear evidence of current rabies vaccination is available. In the event that a wild animal caused the bite, or the animal in question is unavailable for quarantine, the person bitten must undergo a post exposure prophylactic (PEP) regimen that entails an injection of anti-rabies immunoglobulin in addition to four doses of rabies vaccine. 40,000 to 50,000 PEP treatments are given to people in the United States every year, suggesting rabies remains a significant problem. ${ }^{4}$ Definitive diagnosis of rabies in animals is impossible ante mortem, as brain tissue must be examined histopathologically for microscopic Negri bodies. In the event of a local epizootic, or when the disease becomes enzootic in a region, the number of PEP treatments administered increases in that region. While costs vary, a course of rabies immunoglobulin and four doses of vaccine typically exceeds $\$ 3,000 .^{4}$

\section{Viral strains and vaccinations}

There are a number of strains of rabies virus, with each being highly adapted to a specific host species, although spillover into other hosts can and frequently does occur. In fact, the labelling of the strains by host species (raccoon, bat, fox, etc.) is only reflective of the species that acts as the primary reservoir for that strain of virus at that time. Either bat or carnivore origin rabies infection can be transmitted to any other mammalian host. It is almost always lethal in all species, including humans, once symptoms have developed, and no effective treatment is available. Only two cases of rabies survival in humans are documented. ${ }^{7}$

In the United States, effective rabies vaccination protocols for domestic animals have resulted in near elimination of the disease in that population. However, viable prevention does not come without an economic burden. The cost of rabies prophylaxis, treatment and control programs is estimated to be between $\$ 250$ and $\$ 500$ million dollars annually. ${ }^{4}$ This includes prophylaxis in 
both domestic and wild animals. Additionally, rabies infection in agricultural settings has significant cost burdens for animal producers. ${ }^{8}$

In wildlife species, effective control and even elimination of rabies virus has been achieved in some species. One strategy employed to attain this goal has been oral rabies vaccination (ORV). The use of ORV has successfully eliminated rabies virus in red foxes (Vulpes vulpes) in several European countries. ${ }^{9}$ In North America, ORV programs resulted in the elimination of arctic fox (Vulpes lagopus) variant rabies in Ontario from red foxes, and in south Texas, a spillover of a canine (Canis familiaris) variant of rabies from Mexico in coyotes (Canis latrans) was successfully contained. ${ }^{10}$ An ORV project involves distribution of baits containing a fishmeal attractant that encloses a sachet of orally active rabies vaccine. ORV baits are distributed from aircraft in rural areas, while hand distribution of baits occurs in urban settings. ${ }^{11}$ The goal of baiting is to achieve a bait density of approximately 75 baits $/ \mathrm{km}^{2}$. The vaccine is a vectored vaccine using a nonvirulent Vaccinia poxvirus vector encoding rabies glycoprotein (VRG), although field testing of other vaccine types is currently underway. Another rabies vaccine, derived from human adenovirus, has been shown to be both safe and effective, and elicits a stronger antibody response than VRG in raccoons. ${ }^{12}$ The published field trial of this vaccine was unable to assess its efficacy in skunks (Mephitis mephitis). ${ }^{12}$ One drawback to VRG is that it has not been effective in producing immunity in skunks, which represent the predominant reservoir species for rabies in the Midwest region of the United States. ${ }^{10}$ It is desirable that a single type of oral vaccine be efficacious for both species, as their habitats tend to overlap.

In West Virginia, the viral strains known to be present are bat and raccoon rabies virus variants. There are several bat strain rabies viruses enzootic in the state historically, with sporadic cases reported from all counties; even so, bat cases represent less than $5 \%$ of the animals found to 
be positive for virus. Raccoon variant rabies virus (RRV) is currently enzootic in the Southeast United States, and expanded its range into the eastern part of West Virginia subsequent to the introduction of translocated rabid raccoons (Procyon lotor) along the West Virginia - Virginia border near Greenbrier County in the late 1970 s. ${ }^{13}$ Since then, RRV was reported to expand at a rate estimated to be between 30 and $60 \mathrm{~km} / \mathrm{yr} .{ }^{14}$ Despite the success of immunization programs in domestic animals, rabies infection has increased in West Virginia's wildlife, particularly in raccoons. Raccoons are of special concern due to their ability to coexist in close association with humans, commonly raiding refuse containers and pet food left outdoors, along with other food sources such as bird feeders.

Prior to the introduction of RRV in West Virginia, there were few (5-10) rabies positive raccoons reported annually, all of which were infected with a bat strain virus. Once the epizootic front moved through, numbers of RRV positive raccoons increased dramatically, peaking in 2002 with 126 positive animals. Moreover, spillover species added 37 positive animals ( $23 \%$ of the total positives) in that year, including eight domestic animals (cats, horses and cows). RRV is especially associated with spillover into other species, and has been described as a "super spreader."15 There has been some speculation that RRV has a propensity to undergo host shifts, where the virus adapts to a new host species and begins independent circulation within that species. ${ }^{15}$ This tendency could result in establishment of a viral reservoir in other species, and potentially even domestic species, if vaccination and control practices are not maintained. The importance of RRV in West Virginia is highlighted by the fact that over $95 \%$ of rabies positive animals identified from $2000-2015$ were infected with RRV. ${ }^{16}$

Cats represent roughly $5 \%$ of the RRV positives identified in peridomestic settings in West Virginia. ${ }^{16}$ This is of particular concern, as many remain unvaccinated for rabies, even though 
rabies prophylaxis is mandatory in West Virginia. ${ }^{17}$ In addition, cats have a propensity to establish viable feral populations. ${ }^{18}$ These factors, and others, contribute to the current situation, where over 2500 animal bites and other potential rabies exposures are reported annually in West Virginia. ${ }^{16}$ Unfortunately, data are not available regarding how many of these are true exposures, nor is a species breakdown of the animals involved.

In response to this outbreak, the United States Department of Agriculture, Animal and Plant Health Inspection Service, Wildlife Services (USDA/APHIS Wildlife Services) began the ORV project to vaccinate raccoons in West Virginia in $2001 .{ }^{11}$ The baits are scattered in a band that runs in a roughly north - south orientation through the center of the state. This is intended to act as a cordon sanitaire to prevent further westward encroachment by the virus. The ORV uses the concept of herd immunity within the baited zone to effect protection of the raccoons from RRV. There is evidence that the program has resulted in reduced numbers of RRV cases in the baited zone, as well as slowing the westward movement of the epizootic wave. ${ }^{19}$ That study examined the 1990-2007 time period, and there has been no published study of the program in the interim.

\section{Requirements for Effective Prevention}

Given the high costs of control and treatment, as well as the significant spillover of RRV into domestic species and the concomitant risk to humans, it seems imperative that improved knowledge of the behavior of RRV be investigated, to examine the temporal and spatial determinants of RRV infection. It should be noted that any rabies positive animal identified is necessarily associated with suspected human exposure warranting testing, and such exposure is increased to the extent that animal collection and handling requires human involvement. 
The emergence and/or expansion of zoonotic infectious diseases has a direct effect on the health of human populations. Based on the principles and practices of disease prevention, control of environmental determinants of zoonotic diseases will result in improved human health. ${ }^{20}$ This project will examine the current dynamics of RRV in West Virginia and the potential implications for improved prevention of human exposures.

\section{Factors Associated with Spread of RRV}

An examination of the current literature indicates that there have been several studies regarding rabies, with many specific to RRV. Rabies is frequently reported in the Eastern United States, where the primary reservoir for the virus is the raccoon. Raccoons represented $32 \%$ of the positive animals nationwide in 2012, 2013 and 2014, although there was a reduction in total numbers of positive raccoons detected of $1.4 \%, 2.8 \%$ and $4.0 \%$, respectively. ${ }^{21-23}$ The disease has been used as a test case for determining the utility of using genomic and environmental data for modelling virus dispersal in emerging epidemics, indicating these data can be useful in testing hypotheses regarding mode and speed of such dispersal. ${ }^{24}$ An early study described the epizootic as moving through Virginia in an eastward direction over the period $1978-1982 .{ }^{25}$ Another study examined the relationship between RRV in skunks and raccoons, finding that the center of RRV in raccoons had migrated west roughly $360 \mathrm{~km}$ in the period from 1990 to 2000, starting in central Maryland and terminating just south of the Northern Panhandle of West Virginia. ${ }^{26}$ There is a relative paucity of published studies regarding temporal analysis of RRV. This is unfortunate, since such information is useful for determining the optimum allocation of limited resources for rabies prevention and control.

Regarding spatial predictors of RRV, several studies are available, although none provides a comprehensive review of all factors and cases involved in the RRV epizootic in West Virginia. 
Available research indicates that the virus is primarily found in a north - south gradient in the Eastern United States, associated with the original focus of RRV in southeastern states and another focus in the mid-Atlantic region subsequent to the translocation of rabid raccoons from that original focus to the West Virginia - Virginia border area in the 1970s. ${ }^{13}$ The resulting RRV outbreak in the mid-Atlantic moved rapidly to the north and east, and reached Canada in $1999 .{ }^{27}$ The two foci have had different time courses with regard to their expansion. The southern focus has expanded slowly, while the mid-Atlantic outbreak spread rapidly, with greater numbers of rabid raccoons reported. This disparity is postulated to be due to the dense human population along the eastern seaboard, combined with raccoons in that region that were immunologically naïve to $\mathrm{RRV}^{27}$ It is of interest that, while eastward and northern expansion occurred with relative ease and rapidity, there is a notable lack of commensurate westward expansion. It has been suggested that this is due to the high ridges to the west, known as the Allegheny Front, acting as a barrier to raccoon (and virus) movement. ${ }^{28,29}$ Studies that have examined this hypothesis are equivocal. A genetic analysis of raccoons in the valley and ridge topography of southwestern Pennsylvania found little evidence of genetic divergence among animals on either side of a ridge, suggesting that the ridge had minimal impact on the movement and genetic interchange between the native raccoons. ${ }^{30}$ Interestingly, the same investigators, using telemetry on individual raccoons in the same area, indicated that there was little evidence of animals crossing the ridge and suggested that the spur valleys that tended to run perpendicular to the ridge acted as corridors for raccoon movement. ${ }^{31}$ They addressed the seeming contradiction between the two studies by pointing out that they had effectively three populations in their study, one on the ridgetop and one in each of the adjacent valleys, and while their study provided little evidence of contact between the valleys, there was contact by animals from each valley with the ridgetop population. ${ }^{31}$ As such, the ridgetop 
animals acted as a conduit for exchange of genetic material between the valleys. It should be noted that the ridge in these studies had an elevation of $2866 \mathrm{ft}$. $(874 \mathrm{~m})$, which is comparable to, or exceeded substantially by, the mean elevation of several counties in eastern West Virginia. Thus, one might hypothesize that the mountainous topography in eastern West Virginia could have a similar effect on raccoon transmigrations.

Another potential barrier to rabies viral movement suggested is bodies of water, especially large rivers. ${ }^{32}$ One study found that there was a sevenfold reduction in the speed of epizootic spread across a river. ${ }^{33}$ Another noted that rivers were particularly effective as barriers when associated with heavy forest cover, with no movement across the river when associated with heavy forestation. ${ }^{34}$ Unfortunately, there are no rivers large enough to act as effective barriers in eastern West Virginia. That area is, however, heavily forested, which was noted to result in a threefold reduction in viral movement. ${ }^{34}$ Hence one might hypothesize that forest edges and peridomestic areas support higher raccoon numbers and/or more raccoon translocations, thereby furthering RRV spread.

Several investigators have examined other environmental and demographic factors. One such study found that human population density, surface water, residential land use, agriculture and industrial development were significantly positively associated with RRV outbreaks, while deciduous and mixed forests reduced the odds of epizootic RRV. ${ }^{35}$ Similarly, a more recent study found that human agricultural land use and rurality were significantly associated with increased risk of human exposure to a rabid raccoon. ${ }^{36}$ However, that study did not include non-raccoon animals that were positive for RRV, nor did it evaluate types of land use beyond agriculture and forestation, human population density or elevation. 


\section{Evaluation of the ORV project in West Virginia}

The ORV project in West Virginia was last evaluated for effectiveness in 2010, using state rabies data for the period 1990-2007. ${ }^{19}$ At that time, the program demonstrated statistically significant effectiveness, based on reduced numbers of RRV cases in the areas baited, as well as a cessation of westward encroachment of the virus. ${ }^{19}$ That study did not examine non-raccoon species however, and there has been no subsequent evaluation of the ORV program. Given that the current data indicate that cases of RRV may be declining, it is of interest to examine whether the rates of decline differ in the baited zone when compared with the enzootic areas to the east.

The collection of projects encompassed by this dissertation had three primary goals. The first was to conduct a purely longitudinal analysis that examined the number of cases by county as collected annually to determine whether there were temporal trends in RRV incidence. A secondary goal of this analysis was an evaluation of the effectiveness of the ORV program.

The second primary goal involved analysis of spatial data to determine whether there were quantifiable spatial characteristics that were associated with RRV incidence, with an associated secondary goal of identifying any clustering of counties with high RRV case numbers. Once the spatial analysis had been conducted, the third study carried out a more complex analysis of the dependent and independent variables that could accommodate autocorrelation and considered changes in the variables over both time and space, in an effort to determine whether there were significant variables that were not apparent in the second study.

Taken as a whole, the three studies compared the newer INLA technique with analysis techniques used in older studies to determine it's utility in identifying risk factors for the spread of RRV with greater specificity. The studies provided insight into the behavior of RRV within 
West Virginia, as well as indicating areas in the state where allocation of constrained public health resources might result in the most benefit. 


\title{
CHAPTER ONE
}

\section{Longitudinal Analysis of Raccoon Rabies Virus in West Virginia, 2000-2015: A Preliminary Investigation}

\begin{abstract}
Animal borne rabies virus is a source of infection in humans, and raccoons (Procyon lotor) are the primary terrestrial reservoir in West Virginia (WV). To assess the behavior and status of raccoon variant rabies virus (RRV) cases in $\mathrm{WV}$, a longitudinal analysis of RRV case numbers for the period 2000-2015 was performed, using data provided by the state Bureau of Public Health. The analytic approach used was negative binomial regression, with exclusion of those counties that had not experienced RRV cases in the study period, with further examination of those counties where oral rabies vaccine (ORV) baits had been distributed as compared with non-ORV counties. These analyses indicated that there had been a reduction in numbers of RRV positive animals over the study period, predominantly due to a decrease in raccoon infections. Non-raccoon hosts did not appear to have a similar decline, however. The rates of decline for the ORV zone were found to be significantly greater as compared to the non-ORV area. The study was limited by the lack of data for season or point location of animal collection, and by lack of surveillance effort data. Even so, this study has implications for the preventive measures currently being implemented, including expanded vaccination effort in domestic animals. Spatial analyses of RRV and further examination of the virus in non-raccoon hosts are warranted.
\end{abstract}




\section{Introduction}

In order to assess the public health risk of rabies virus to humans in WV and the current state of rabies virus prevention efforts and evaluate the temporal effects of the ORV program, the aim of this study is to determine whether there has been a significant change in the number of RRV cases over the period 2000-2015 in WV. This was accomplished by using counties where RRV was reported, and among these counties, comparing those where the ORV program has been active with those where RRV is enzootic but ORV has not been deployed. Hypotheses tested will be that there are significant reductions in RRV cases overall, and that there are significant differences between the rates of decline in the counties where ORV has been implemented as compared to the RRV enzootic counties, in all animal groups. The analytic approaches employed were used to evaluate the data while accounting for the uneven distribution of rabid animals, and while including all types of affected animal hosts in the analysis.

\section{Materials and Methods}

\section{Data collection and database structure}

Data used here came from the WV State Bureau of Public Health and consisted of the annual state reported rabies virus case database for RRV. These data, as used here, represented county level data for the years 2000 to $2015^{16}$. This is a complete dataset, including all cases of rabies virus hosts by species identified in the state during the study period, the county where they were collected and viral variant.

Identifying suspect animals for the analysis used here typically relied on one of the following situations:1) animals involved with biting or scratching humans, 2) animals involved 
with biting or scratching domestic animals or livestock, 3) the opportunity to observe an animal exhibiting an atypical behavior, or 4) results of an occasional environmental "spot check" ${ }^{37}$. Also included in the database are animals collected by the USDA/APHIS Wildlife Services subsequent to implementation of the ORV program. Unfortunately, data are not available regarding how many of these were human exposures (defined as a bite or a scratch).

Generally, suspect animal brains were submitted by veterinarians or animal control personnel to the state diagnostic laboratory for direct fluorescent antibody screening ${ }^{37}$. Also, animals that tested positive subsequent to trapping and testing by the USDA/APHIS Wildlife Services are included in the database. All positive samples from either source were submitted to the $\mathrm{CDC}$ for confirmatory testing and viral variant identification. Viral detection was performed at $\mathrm{CDC}$, using direct fluorescent antibody testing, with subsequent variant typing performed using a validated RT-PCR method ${ }^{38}$.

There were 1569 animals found to be positive for any rabies virus during the study period. Only those cases specifically identified to have RRV infection ( $n=1464,93.3 \%)$ were retained for evaluation, with cases showing unspecified viral variant $(n=23,1.5 \%)$ or bat variant $(n=82,5.2 \%)$ excluded. Unfortunately, the database does not provide numbers of uninfected animals tested, and it was not possible to assess data accuracy independently.

Data regarding human population size by county were obtained from the US Census bureau using data from the 2000 and 2010 Censuses, in addition to the intercensal estimates for intervening years ${ }^{39}$, and human population density was calculated using county areas, as provided by the U.S. Geologic Survey in the 2006 National Land Cover Database ${ }^{40}$. All data were compiled in Microsoft Excel spreadsheets. 


\section{Data analyses}

The statistical programming platform $\mathrm{R}$ (version 3.4.2) was used to evaluate the data, employing the glmmADMB package (version 0.8.3.3) ${ }^{41,42}$. This package was chosen due to its ability to handle a wide variety of modelling approaches, thereby maintaining consistency of analysis. Given that the data were count data, Poisson and negative binomial distributions were considered for possible use. During exploratory analysis, the overall mean annual number of cases was found to be 1.66 , with a variance of 13.94 . This indicated that the data were over-dispersed and that negative binomial modelling was most appropriate. However, negative binomial modelling requires an offset variable to denote the population at risk in each cluster during regression, and to reflect different weighting of the data clusters. Although the preferred offset would be total raccoon population in each county, these data are not readily available. Several potential candidate offsets were evaluated in exploratory analyses, including area (in $\mathrm{km}^{2}$ ) of counties, total county human population and county human population density. It became evident that these potential offsets were essentially equivalent, both in coefficient value as well as p-value. Given the known behavior of raccoons and their propensity to inhabit areas in close proximity to human activity, human population density in each county was selected as the offset, as it was believed to be most likely to be proportional to actual raccoon populations ${ }^{43}$. In addition, human population density is also relevant to exposure risk, insofar as the majority of animals submitted came through the public health surveillance system following human or domestic animal exposures.

Several counties in the western portion of WV had no positive samples for RRV throughout the study period, as a result of the failure of RRV to reach these western areas. It was decided to restrict the analysis to those counties that had at least one positive sample in the period 2000-2015 
(Table 1.1). The state was divided into three zones. Zone 1 included all counties that experienced no RRV positives during the study period and thus were excluded from the analysis. Zone 2 comprised those counties that reported a RRV positive animal and where ORV baits were distributed for the years 2005 - $2015^{11,44}$, and Zone 3 was all remaining counties where RRV was reported but ORV was not deployed (see Table 1.1 and Figure 1.1). Analyses were run for all host species combined, as well as for raccoons, nondomestic non-raccoons (NDNR) and domestic animals separately. The NDNR grouping includes all non-raccoon wildlife. Additionally, the combined zones, as well as each zone separately, were analyzed for each of these animal groups.

A z-score analysis was performed to detect whether there were significant differences between the two zones for each host animal group, as well as for the combination of all animal hosts. Z-scores, and associated p-values, were calculated using the standard errors and coefficient values derived from the negative binomial analyses. All models were run using $\alpha=0.05$ as the significance threshold.

\section{Results}

There were 1464 RRV positive animals during the study period, from 2000-2015. These were comprised of 962 raccoons, 391 NDNR and 111 domestic animals. A complete species breakdown of the positive samples in non-raccoons is provided in Table 1.2. Preliminary examination of the state RRV data from 2000-2015 seems to show an overall decreasing trend in the number of animal RRV cases over that timeframe, as shown in Figure 1.2. However, there does not appear to be a similar decline in cases for the NDNR and domestic animal hosts. 
The negative binomial model was fit for zones 2 and 3 combined, using log human population density as the offset, yielding a regression coefficient of -0.06 with a $p$-value of $<0.001$ as shown in Table 1.3. When analyzed separately, zone 2 had a regression coefficient of -0.09 with a p-value of $<0.001$, while zone 3 had a regression coefficient of -0.04 with a p-value of $<0.001$. In these models the coefficients can be interpreted as follows: the mean number of cases in logscale for zones 2 and 3 combined was reduced by 0.06 per year for 16 years, which is equivalent to a reduction of 1.062 cases per year for 16 years. The result for zone 2 was equivalent to a reduction of 1.094 cases per year, while the result for zone 3 translates to a reduction of 1.041 cases per year.

Negative binomial models were fit for each of the three animal types in this study, and the results are shown in Table 1.4. Raccoons were found to have regression coefficients of -0.083, 0.102 and -0.061 , all with p-values of $<0.001$ for the zones combined, Zone 2 , and Zone 3 respectively. All of these values are indicative of an increased rate of decline as compared to the results obtained for the total numbers of RRV positive animals. NDNR hosts in the zones combined had a regression coefficient of -0.02 , with a p-value of 0.18 , while zone 2 had a regression coefficient of -0.032 , and a p-value of 0.21 . Zone 3 yielded a regression coefficient of -0.015 , and a p-value of 0.4 for NDNR. Finally, domestic animals had a regression coefficient of 0.013 and a p-value of 0.62 for the zones combined. Zone 2 had a coefficient of -0.018 and a pvalue of 0.66 for domestic animals, while the same group in zone 3 had a coefficient of 0.037 and a $p$-value of 0.29 . These results indicate that while there was a significant $(\mathrm{p}<0.001)$ reduction in raccoon infection, no such significant reduction was detected in non-raccoon hosts, whether nondomestic or domestic ( $\mathrm{p}=0.18$ and 0.62 , respectively). The declines in RRV cases were statistically significant for all hosts combined, as well as raccoons, in all areas examined. 
The results of the z-score analyses are presented in Table 1.5. When comparing the model results between Zones 2 and 3, all host species combined and raccoons were found to have significant differences (p-values of 0.01 and 0.047 , respectively) in the rate of decline. No such significance was found for NDNR and domestic animals (p-values of 0.291 and 0.15 , respectively).

\section{Discussion}

There have been several studies regarding rabies virus infection, with many specific to RRV. Rabies virus is frequently reported in the eastern United States, where the primary reservoir for the virus is the raccoon ${ }^{15}$. Raccoons represented $32 \%$ of the positive animals nationwide in 2012, 2013 and 2014, although there was a reduction in total numbers of positive raccoons detected for these years of $1.4 \%, 2.8 \%$ and $4.0 \%$, respectively ${ }^{21-23}$. Many prior studies regarding RRV have tended to focus on cases in raccoons and a limited number of other species (skunks, cats, rodents), without examining cases in other domestic and NDNR animals ${ }^{26,45,46}$. One study that did examine all species infected with RRV was primarily focused on the economic costs of rabies prevention

47. Similarly, there have been relatively few published studies regarding longitudinal analysis of RRV that have examined all infected hosts in a specific region and time period with the intent of comparing the incidence of RRV in those hosts ${ }^{27,47,48}$.

Since the inadvertent introduction of RRV into the Mid-Atlantic States, the disease has spread throughout the region and into New England and Canada ${ }^{34,49,50}$. The primary finding of the current analysis is that there has been a significant decline in all RRV positive animals in zones 2 and 3 during the study period, with the bulk of the decline in positives occurring in raccoons in all areas examined. The rate of decline in Zone 2 is significantly greater, indicating the impact of the ORV program on RRV in that area. Substantial resources have been used in WV to control rabies 
virus in raccoons with apparent success ${ }^{9,12,51,52}$. However, the decline in RRV cases does not extend to non-raccoon hosts. Regardless, control efforts do not appear to have significantly affected RRV infection in other hosts, as demonstrated by the results of the analysis (Table 1.4). Additionally, no difference between the zones was found with regard to non-raccoon hosts. The uncoupling of RRV exposure and vaccination efficacy from raccoons to other hosts suggests control efforts may enable the virus to become established in non-raccoon hosts, where it could begin to circulate independently from the raccoon reservoir. The most likely hosts that could serve as this potential reservoir would be skunks and red foxes, especially given that these hosts act as the primary host reservoir in other areas of North America. Skunks act as reservoir hosts in the central United States, while red foxes have been reservoirs historically in Canada ${ }^{21-23}$. This would be plausible if RRV has the postulated ability to spillover into non-raccoon hosts and potentially establish itself in new reservoir host animals ${ }^{15}$. However, our study did not show any evidence of their involvement as a reservoir at this time.

Our results are consistent with the results reported by Wallace et al. When we calculated cross species transmission (CST) rates as described in their paper (\# non-raccoon cases/\#raccoon cases), we obtained overall rates, as well as skunk and fox rates $(0.52,0.30$ and 0.07 respectively), that were comparable to those found by the Wallace team in $2011(0.73,0.35$, and 0.18$){ }^{15}$. It may be encouraging that the CST rates found in our study were consistently lower than those found in 2011 by Wallace. However, our optimism is tempered by the finding that when CST rates in WV for 2011 are calculated, the overall rates, and those for skunks ( 0.86 and 0.54 , respectively), were substantially greater than those the Wallace group reported for 2011 previously, although the CST rate for red foxes $(0.08)$ was less than half that found by Wallace. ${ }^{15}$ 
Interestingly, when CST in 2011 is examined for each of the zones, Zone 2 had markedly higher rates than Zone 3 for all CST, as well as skunk (0.84 and 0.67 vs. 0.63 and 0.33 , respectively), while CST in red foxes was substantially lower for Zone 2 (0.03 vs.0.13). While these samples are too small to make statistical inference, they are of interest nonetheless.

The findings of a reduction in RRV cases in raccoons due to ORV are consistent with the available literature. For example, Ma et al noted a general reduction in numbers of RRV positive raccoons recovered in areas of $\mathrm{WV}$ where $\mathrm{ORV}$ occurred, subsequent to the commencement of the ORV program ${ }^{19}$. Their study examined raccoons in a limited number of counties where ORV had been provided, however, and compared them to the eastern WV counties where RRV is enzootic. Here we extended their observations to include RRV induced disease in non-raccoon animals, both domestic and non-domestic, and all counties where ORV was deployed. Their data extended up through 2007 and captured 2002, the peak year of RRV positives in the state shown in Figure 1.2. The current study period continues through 2015 and includes additional peaks in 2009 and 2011. The peaks described by Ma et al, and those seen in the current study, are consistent with prior descriptions of epizootic and inter-epizootic RRV, where the first epizootic was largest, with subsequent, smaller epizootics ${ }^{46,48}$.

There are several potential reasons for the overall reduction in RRV incidence over the study period. The ORV project is well established in the state, and our work and that of Ma et al clearly show it is having a significant effect on overall RRV numbers ${ }^{19}$. Additionally, given the rapidly fatal progression of the disease in infected animals, it is possible that it is "burning itself out" and has reached, or is reaching, a self-limiting steady state. Fluctuations in state and local human populations may also be affecting raccoon numbers, and subsequently influencing contact rates with infected animals. 
The temporal pattern of RRV infection in non-raccoon animals may be cause for concern. Although prior studies have indicated that it may not be the case in cats ${ }^{46}$, one would anticipate that as the numbers of RRV positive raccoons decline, numbers in non-raccoon hosts would experience a similar decline. This is not borne out by the data examined here. NDNR and domestic hosts had no significant changes in RRV positive animals. This would indicate that RRV is not experiencing a decline in these animal hosts, and could be conducive to the virus becoming independently established in other reservoir(s) (e.g. skunks and foxes) where baits are not effective. The fact that neither NDNR nor domestic hosts is declining tends to decrease the likelihood that this is simply a reflection of diminished domestic animal vaccination practices. The rates of vaccination are likely to be higher in dogs than in livestock or cats (especially feral cats), and this may be reflected in the higher numbers of positives found in cats and cattle. The maintenance of steady RRV incidence is of particular concern in domestic animals, even though they are not a likely alternative host reservoir, as these are most likely to have close contact with humans. Additionally, there were a number of cases in livestock hosts (such as horses, cows, sheep and goats). Although less frequently encountered than in domestic carnivores, these cases may actually represent a greater risk to humans due to a lowered index of suspicion among farmers or veterinarians caring for these animals. Unrecognized exposures in turn could cause significant delay in proper diagnosis of these infections, potentially allowing owners and others to have greater risk of serious disease.

Limitations: The data available constrained the current study. Given that the data provided are restricted to county and year of collection, it is impossible to examine seasonal patterns or perform more detailed geographic analysis. Additionally, it is difficult to assess whether the animals submitted for testing are truly representative of the disease as it exists in the larger natural 
population of these hosts within the state. It seems likely that these animals represent a biased sample of the population as a whole. This bias could easily result in an underestimation of the true impact of RRV. Finally, the limited number of submissions of non-raccoon animals, both domestic and wild, may place constraints on accurate assessment of the longitudinal trend in these hosts.

Another significant limitation of the study is the lack of data regarding the species and total number of all animals tested. As a result, it is difficult to assess whether surveillance efforts remained consistent throughout the study period. However, it seems likely that surveillance efforts would have remained constant, or may have increased, due to the implementation of the ORV program, to determine its efficacy and to justify continued funding. This potential elevation of surveillance would be unlikely to extend to host species other than raccoons, nor would it likely extend beyond the counties where the ORV program was implemented and would be unlikely to have resulted in the reduction in RRV cases found in this study.

\section{Conclusion}

This study demonstrates that numbers of RRV positive animals declined significantly over the study period in those areas of the state of WV where RRV is enzootic, particularly in the primary viral reservoir host, raccoons. There is no reason to assume that diagnostic or recovery methods have changed during this same period. The results of this study would indicate that public health efforts are needed to improve vaccination rates in all domestic animals, including livestock, especially in those counties where RRV is enzootic. Public information campaigns targeted at veterinarians and livestock owners could be instituted in those areas to increase awareness of the risk of rabies infection. Further examination of RRV in non-raccoon hosts seems warranted to explain why these diverse groups are not trending down along with the raccoons. Future directions

for this work include a spatial analysis of those factors that may be associated with RRV and 
raccoon populations, including land use, human population density and availability of surface water as well as ambient weather conditions. Additionally, cluster analysis of RRV positives would provide useful information to use as guidance for RRV control and other public health measures. 
Table 1.1: Counties contained within each of the zones, West Virginia.

\begin{tabular}{|c|l|}
\hline $\begin{array}{c}\text { Zone 1 } \\
\text { Counties that reported no RRV cases in the } \\
\text { study period } \\
(\mathrm{n}=22)\end{array}$ & $\begin{array}{l}\text { Boone, Cabell, Calhoun, Clay, Doddridge, } \\
\text { Gilmer, Jackson, Kanawha, Lincoln, Logan, } \\
\text { Mason, McDowell, Mingo, Pleasants, } \\
\text { Putnam, Ritchie, Roane, Tyler, Wayne, Wirt, } \\
\text { Wood, Wyoming }\end{array}$ \\
\hline $\begin{array}{c}\text { Zone 2 } \\
\text { Counties that reported at least 1 RRV case } \\
\text { and had ORV baits distributed during the } \\
\text { study period } \\
(\mathrm{n}=24)\end{array}$ & $\begin{array}{l}\text { Barbour, Braxton, Brooke, Fayette, } \\
\text { Greenbrier, Hancock, Harrison, Lewis, } \\
\text { Marion, Marshall, Mercer, Monongalia, } \\
\text { Monroe, Nicholas, Ohio, Pocahontas, Preston, } \\
\text { Randolph, Summers, Raleigh, Taylor, } \\
\text { Upshur, Webster, Wetzel, }\end{array}$ \\
\hline $\begin{array}{c}\text { Counties that reported at least 1 RRV case } \\
\text { and did not have ORV baits distributed during } \\
\text { the study period } \\
(\mathrm{n}=9)\end{array}$ & $\begin{array}{l}\text { Berkeley, Grant, Hampshire, Hardy, } \\
\text { Jefferson, Mineral, Morgan, Pendleton, } \\
\text { Tucker }\end{array}$ \\
\hline
\end{tabular}

Each county within West Virginia was assigned to a zone based on the presence/absence of RRV as well as whether ORV baits were distributed during the study period, 2000 - 2015 
Figure 1.1: Map of the zones in West Virginia, as designated for this study

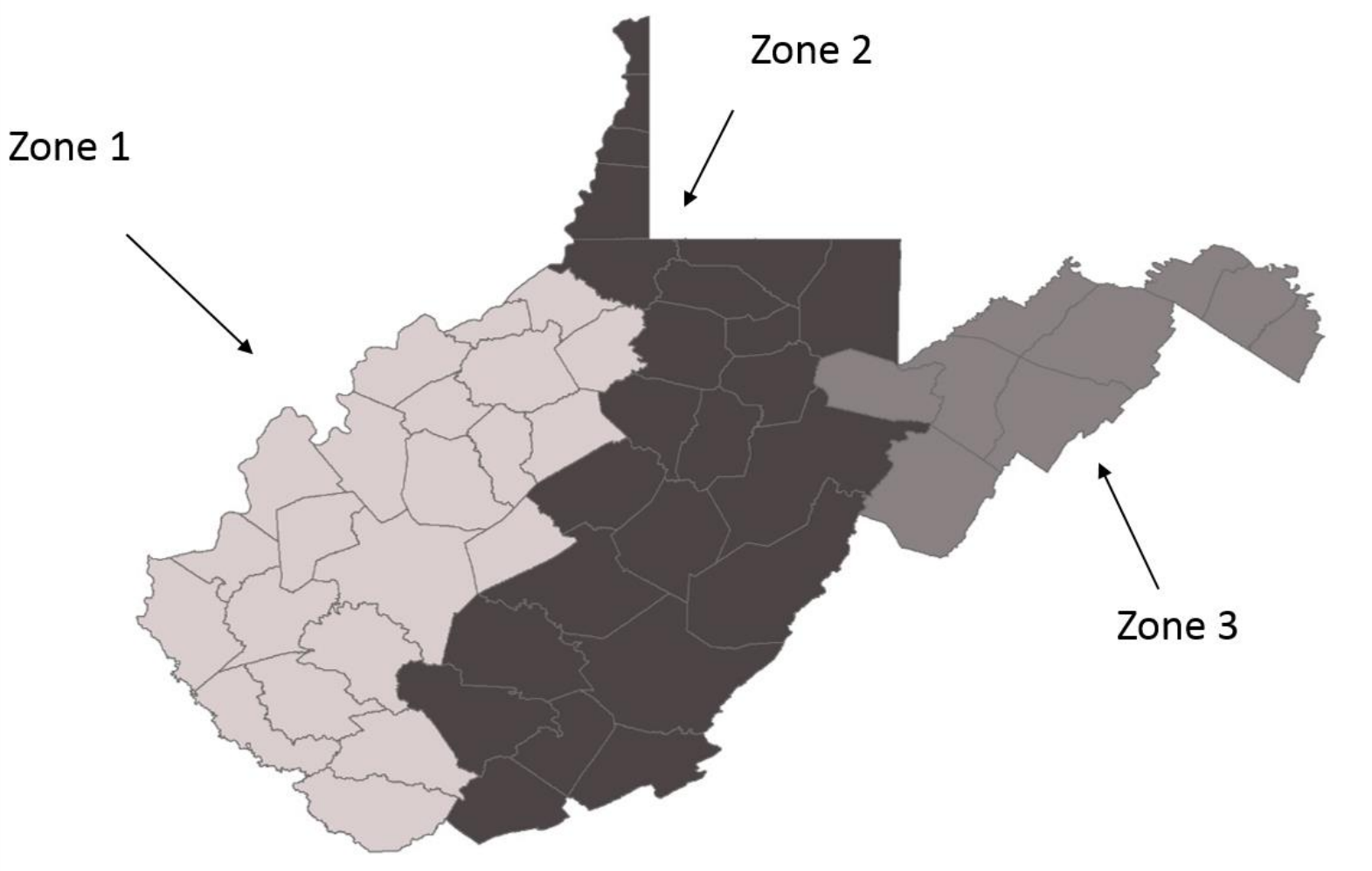

A map of the three zones for the state of West Virginia as determined by raccoon variant rabies virus (RRV) presence and oral rabies vaccine (ORV) distribution (Zone $1=$ No RRV during study period, Zone $2=\mathrm{RRV}$ present and ORV distributed, Zone $3=\mathrm{RRV}$ present, ORV not distributed). 
Table 1.2: Species breakdown of all non-raccoon wildlife and domestic animals infected with raccoon variant rabies virus, West Virginia, 2000-2015.

NDNR species

Striped skunk (Mephitis mephitis)

Red Fox (Vulpes vulpes)

Bobcat (Lynx rufous)

Groundhog (Marmota monax)

Beaver (Castor canadensis)

Opossum (Didelphis virginiana)

River otter (Lontra canadensis)

Bat (Species unknown)

Total NDNR

\section{Domestic species}

Cat (Felis catus)

Cow (Bos taurus)

Dog (Canis lupus familiaris)

Horse (Equus caballus)

Goat (Capra aegagrus hircus)

Sheep (Ovis aries)

Total Domestic

\section{Number of RRV positive samples}

290
70
14
10
4
1
1
1
391

290

70

14

10

4

1

391

73

15

8

8

4

3

111

Species and case count for nondomestic, non-raccoon (NDNR) animals and domestic animals diagnosed with raccoon variant rabies virus (RRV), West Virginia, 2000-2015. 
Figure 1.2: Numbers of raccoon variant rabies virus cases by animal type and year, West Virginia, 2000-2015.

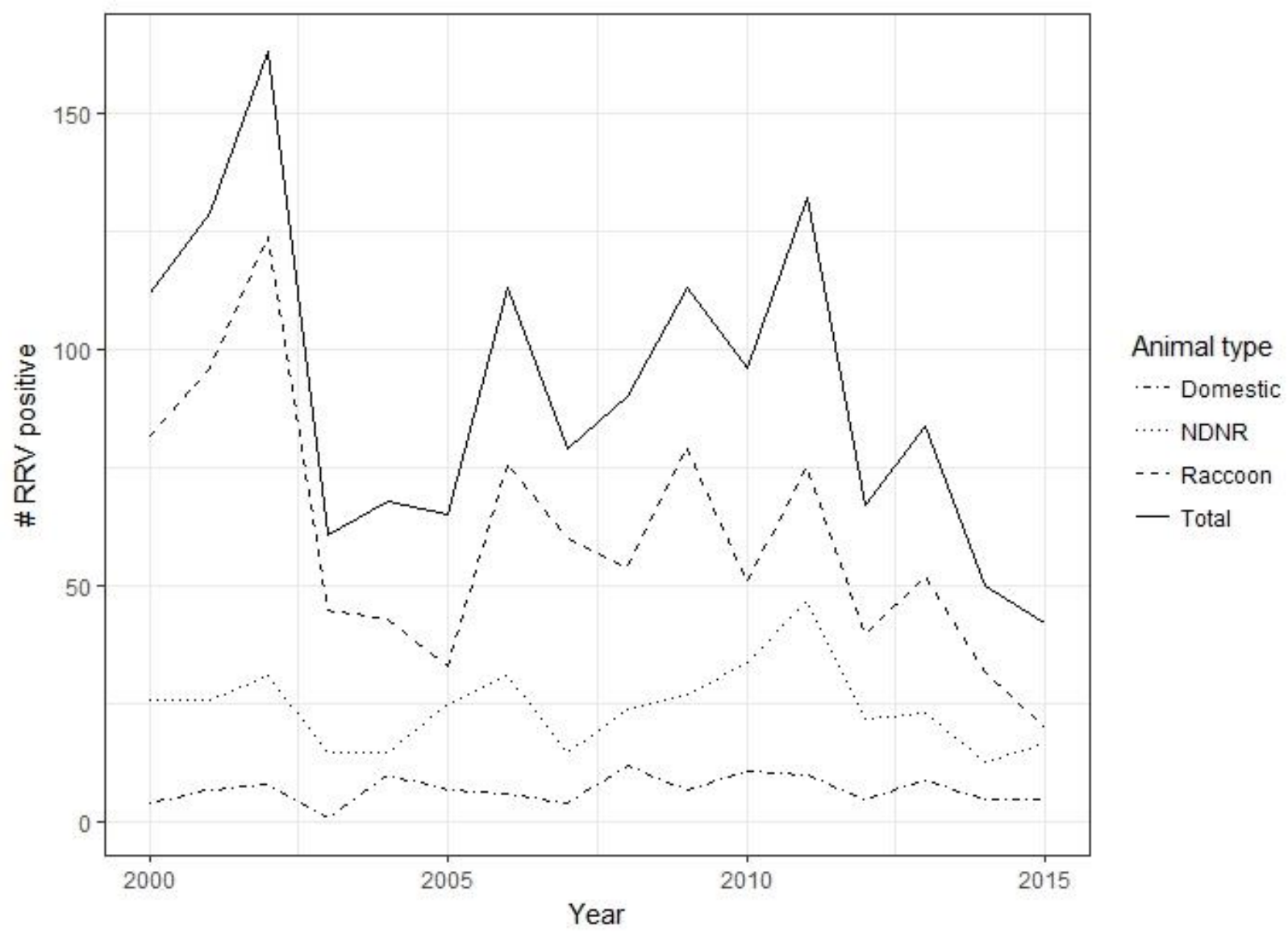

Graph showing trends in raccoon variant rabies virus cases for the varying animal types in this study, West Virginia, 2000-2015. Note that the overall declining trend in total cases and raccoons does not hold for NDNR and domestic animals.

NDNR $=$ Nondomestic, non-raccoons (all non-raccoon wildlife) 
Table 1.3: Comparison of negative binomial models fit for RRV in all hosts, West Virginia, 2000-2015.

$\begin{array}{lcc}\text { Area Analyzed } & \text { Coefficient (SE) } & \text { p-value } \\ \text { Zones } 2 \& 3 \text { combined } & -0.06(0.011) & <0.001 \\ \text { Zone } 2 & -0.09(0.018) & <0.001 \\ \text { Zone } 3 & -0.04(0.012) & <0.001\end{array}$

Negative binomial models were fit for RRV in all host species. All models show significant declines in RRV cases in each zone. 
Table 1.4: Comparison of negative binomial models fit for RRV in the different animal types and zones, West Virginia, 2000-2015.

$\begin{array}{ccc}\begin{array}{c}\text { Animal type } \\ \text { Raccoon }\end{array} & \begin{array}{c}\text { Regression } \\ \text { coefficient (SE) }\end{array} & \text { p-value } \\ \text { Zones 2 \& 3 } & -0.083(0.013) & <0.001 \\ \text { combined } & -0.102(0.02) & <0.001 \\ \text { Zone 2 } & -0.061(0.014) & <0.001 \\ \text { Zone 3 } & -0.02(0.015) & \\ \text { NDNR } & & 0.18 \\ \text { Zones 2 \& 3 } & -0.032(0.025) & \\ \text { combined } & -0.015(0.018) & 0.21 \\ \text { Zone 2 } & 0.40 \\ \text { Zone 3 } & 0.013(0.026) & 0.62 \\ \text { Domestic Animals } & & \\ \text { Zones 2 \& 3 } & -0.018(0.04) & 0.66 \\ \text { combined } & 0.037(0.035) & 0.29 \\ \text { Zone 2 } & \end{array}$

Negative binomial models regression coefficients, p-values and AIC for the various animal types in this study. Note that while raccoons showed significant declines in all models, NDNR and domestic animals did not show similar significance.

${ }^{\text {a }}$ NDNR $=$ Nondomestic, non-raccoon (all non-raccoon wildlife) 
Table 1.5: Results of z-score analyses comparing Zone 2 with Zone 3 for all hosts, West Virginia, 2000-2015

$\begin{array}{ccc}\text { Group } & \text { z score } & \text { p-value } \\ \text { All host species } & -2.31 & 0.010 \\ \text { Raccoons } & -1.67 & 0.047 \\ \text { NDNR }^{\mathrm{a}} & -0.55 & 0.291 \\ \text { Domestic animals } & -1.03 & 0.150\end{array}$

Z-scores indicate there is a significant difference in RRV decline for Zone 2 as compared to Zone 3 for all hosts and raccoons, with Zone 2 having a greater decline. There was not a significant difference between the zones for NDNR and domestic hosts.

${ }^{a}$ NDNR $=$ Nondomestic, non-raccoons (all non-raccoon wildlife) 


\title{
CHAPTER TWO
}

\section{Exploratory Spatial Analysis of Raccoon Variant Rabies Virus, West Virginia, 2000-2015}

\begin{abstract}
Raccoon variant rabies virus (RRV) has become a significant problem in large portions of the eastern United States, in part stemming from the translocation of rabid raccoons along the West Virginia - Virginia border. Given the rapid expansion of the virus to the east and north subsequent to this release, it is of interest that there has been relatively slow viral movement to the west into West Virginia, especially given the state's geographic proximity to the release site. The objective of the current study is to identify clusters of RRV infection, and explain spatial variation in RRV infection among captured animals. Data were extracted from the database maintained by the West Virginia Bureau of Public Health, and combined with national data collected on geographic location, elevation and type of land use. Analyses consisted of Poisson regression within a Bayesian environment that included consideration of spatial autocorrelation. These analyses, combined with cluster analysis, were performed for several different animal host types. Although multivariable regression analyses failed to demonstrate associations, individual univariate regression and cluster analyses did identify geographic associations. For many of the variables examined, there was statistically significant clustering of RRV cases for all host types, and this analysis provides valuable information that can inform the allocation of prevention resources.
\end{abstract}




\section{Introduction}

Several investigators have examined environmental and demographic factors that may be involved in rabies disease dynamics. One such study found that human population density, surface water, residential land use, agriculture and industrial development showed a significant positive association with RRV outbreaks, while deciduous and mixed forests reduced the odds of epizootic RRV ${ }^{35}$ Similarly, a more recent study found that human agricultural land use and rurality were significantly associated with increased risk of human exposure to a rabid raccoon. ${ }^{36}$ However, that study did not evaluate types of land use beyond agriculture and forestation, nor did it examine human population density or elevation. Additionally, that study failed to consider the potential influence of RRV in adjacent counties on reported incidences levels a given county.

The objective of the current study is to identify clusters of RRV infection and explain spatial variation in RRV infection among captured animals, through a combination of univariate and multivariate spatial regression analyses. Additionally, cluster analysis and Poisson regression were performed to determine whether there were covariates associated with RRV infections that could help explain the differences in reported RRV incidence. Analyses were conducted on all RRV hosts, as well as subpopulations that included raccoons, nondomestic non-raccoons (NDNR) and domestic animals. The NDNR subgroup included all non-raccoon wildlife, such as foxes and skunks, infected with RRV.

\section{Materials and Methods}

\section{Data collection and database structure}

This study incorporated the same rabies data examined in the prior study. Longitude and latitude for the centroid of each county were obtained from the United States Geologic Survey's 
(USGS) Geographic Names Information System. ${ }^{53} \mathrm{~A}$ centroid is defined as the geographical center of a given county, representing the single point within the county furthest from all its borders. Using the centroid located each county geographically relative to each other. Data regarding the mean elevation of each county were obtained by accessing the 30m USGS National Elevation Dataset (NED) Digital Elevation Model (DEM) for West Virginia. ${ }^{54}$ Data for the human population of each county were extracted from the US Census Bureau's datasets, including the intercensal datasets, ${ }^{39}$ with an intercensal dataset being the Census Bureau's annual estimate of county population for the years intervening between official censuses. Land use data was obtained from the Multi-Resolution Land Characteristics Consortium National Land Cover Database (NLCD). ${ }^{40}$ Several codes used in the original database were combined, resulting in six categories of land use (Developed, Forested, Water/wetland, Agricultural/Open, Barren, and Shrubland). Land use percentages reflected the amount of the total land area in a county devoted to each of the land use types. The NLCD also provides information on the total area of each county, which, combined with census data, permitted calculation of county human population densities. The U.S. Department of Agriculture's urban influence codes (UIC) ${ }^{55}$ were used to classify counties as rural or urban. UICs divide counties into 12 groups based on population size. Rural/urban status was given a binary code, with counties in groups one and two considered urban (coded as 1), while all other counties were considered rural (coded as 0 ). Another binary variable was created for border status of counties, with counties bordering Virginia (VA) being coded as 1, while counties without this attribute were coded as 0 ,

\section{Analytic approaches}

Cluster identification was performed using the open source software tool GeoDa, which provides cluster maps and calculates univariate local Moran's I. ${ }^{56}$ Moran's I is a weighted 
correlation coefficient used to detect departures from spatial randomness and indicates the existence of spatial clustering. It typically ranges from -1 to 1 , with random spatial distributions having a value of zero. Departures from randomness indicate spatial patterns, with positive values indicating spatial autocorrelation or clustering. ${ }^{57,58}$ Univariate local Moran's I was calculated and subsequent local indicators of spatial autocorrelation (LISA) maps were produced. Queen's contiguity weights matrices were utilized to maximize consideration of neighboring county values, and results were permuted 99,999 times to increase our ability to detect spatial outliers, while still reducing the probability of identifying spurious clusters. The cluster analyses used a pseudo pvalue threshold of 0.05 , and was performed by pairing each of the outcome variables within a given county with its corresponding Federal Information Processing Standard (FIPS) number. FIPS is a system that gives each county in the country a unique identifier.

Data were collected annually over the 2000-2015 study period. Demographic, land use and geographic data were combined to produce a spatial regression model. The statistical programming platform $\mathrm{R}$ (version 3.4.2) was used to evaluate the data, employing the CARBayes package (version 5.0). ${ }^{41,59}$. This package was chosen due to its ability to perform spatial regression analysis using conditional autoregression (CAR) within a Bayesian statistical environment. CAR analysis assumes the probability of values estimated at any given location is conditioned on the levels of neighboring values. Bayesian analysis was deemed most appropriate, as that approach assumes that prior values influence subsequent data points. The approach incorporated in the CARBayes package uses Markov Chain Monte Carlo (MCMC) simulation and a simple random walk for updates to the random effects. ${ }^{60-62}$ A number of MCMC simulations $(20,000)$ were used as a burnin to allow the model to converge, after which 100,000 simulations were run. These were then thinned by a factor of five to reduce the effect of autocorrelation, and convergence was checked 
by visual examination of convergence plots. An alpha of 0.05 was used as the significance threshold for all analyses.

Since count data were being examined, either Poisson or negative binomial regression techniques were appropriate. Poisson regression was selected as the statistical technique to be used with human population density as the offset, because the Poisson gamma distribution is commonly

used for disease mapping. ${ }^{63-65}$ All outcome variables were aggregated for the entire study period (2000-2015), and mean values for the study period were calculated for all potential continuous covariates, which were then centered by subtracting those means from each data value. For meaningful interpretation of results, mean elevations and county sizes were divided by 100 , and county populations were divided by 1000 . Univariate and multivariate models were evaluated.

\section{Results}

Examination of the data for each host type indicated that there was evidence of statistically significant spatial clustering as shown by Moran's I values in excess of 0.35 . The values for all hosts, raccoons, NDNR and domestic animals were $0.47,0.40,0.50$ and 0.56 respectively. Cluster mapping demonstrated that while the counties involved in the clusters varied among host types, the clustering of cases occurred consistently among certain counties within WV. All of these counties are located along the state's border with VA and/or in the Eastern Panhandle. The number of counties included within clusters ranged from five (raccoon hosts) to eight (domestic animal hosts).

Univariate regression analysis suggested that several variables were correlated with RRV incidence. These variables, along with their associated posterior medians and $95 \%$ credible intervals, are given in Table 2.1 for each of the host animal types. 
When all hosts were evaluated, elevation, county size, percentage of shrubland land use and VA border proximity showed positive associations with numbers of RRV cases, with coefficients of $0.18,0.12,4.61$ and 1.84 respectively. When raccoon hosts were examined separately, an identical pattern of positive associations emerged for univariate regression models incorporating all counties (coefficients of $0.18,0.13,4.64$, and 1.60). However, in addition, developed land use was negatively associated with cases (-0.19). The NDNR data presented difficulties with regard to model convergence. In particular, the percentage of shrubland for all counties would not produce a convergent regression model. This may reflect the heterogeneity of host species within the NDNR grouping, although the majority $(376,96 \%)$ of hosts were mesocarnivores, with skunks accounting for the bulk of these (290, 77\%). Among NDNR hosts, mean elevation was the sole variable that exhibited positive association $(0.23)$ for the univariate models, with RRV cases increasing with elevation. The predictors for domestic animals closely mirrored those for raccoons, in that elevation, county size, and VA border status were each positively associated with case numbers, while cases decreased as the percentage of developed land increased (coefficients of $0.17,1.85,1.99$ and -0.23 respectively). In addition, the percentage of shrubland, which was found to be positively associated in the raccoon models, did not maintain that association when the univariate regression models for domestic animals were examined.

Multivariate analyses were performed, but did not add any new information to that obtained from the univariate analyses. A similar result was observed when an interaction term with any potential predictors.

\section{Discussion}

The purpose of this exploratory study was to examine the distribution of RRV in WV, as well as determine the spatial and demographic variables that might serve as predictors for RRV 
cases and/or outbreaks. While our earlier work indicated that the overall number of RRV cases in WV declined during the study period, there had not been a corresponding decline in non-raccoon wildlife or domestic animals. ${ }^{66}$ We examined spatial clustering of RRV cases, in addition to a number of potential predictor covariates, in the same spectrum of host types as our prior study. ${ }^{66}$ Spatial clustering of RRV cases was present, as shown by Moran's I and cluster mapping, with all clustered counties located along the eastern border with VA and/or in the Eastern Panhandle of WV.

Our study indicates that mean county elevation, county size and border status are most consistently associated with elevated case counts for RRV. While none of these variables is modifiable, they do help define areas in the state that could be viable targets for public health interventions. Finding a positive association with elevation may be a confounder for border status, as many of the counties with higher elevations are found along the WV-VA border. A likely explanation for the consistent and substantial positive association of RRV cases with VA border status is that of a border, or edge, effect. This occurs when a border, that does not actually prevent movement across that border, defines the study area. In this case, the state line is a purely political boundary, which has no effect on the movement of animals across the line. As a result, any geographic distribution or spatial interaction may extend across the WV state border. ${ }^{67,68}$

With regard to variables that are likely to vary over time, the percentage of county area that is developed was most consistently negatively associated with RRV infection, especially in the raccoon and domestic animal groupings. This finding may seem counterintuitive, given the known propensity of raccoons to prefer habitats in peridomestic settings, ${ }^{43,69,70}$ but could indicate that as development proceeds in a given county, case numbers should decline. The positive association with shrubland found for all hosts and raccoons may be spurious, because only seven of the 33 
counties in the study had any shrubland at all, and in those counties, the range was $0.01 \%$ to $0.15 \%$. These low numbers are probably due to improvements in satellite sensing technology that recently have permitted shrubland identification.

Regarding spatial predictors of RRV, several studies are available, although none provides a comprehensive review of all factors and cases involved in the RRV epizootic in West Virginia. Available research indicates that the virus is primarily found along a north - south gradient in the Eastern United States. ${ }^{27}$ The RRV outbreak subsequent to the release of rabid raccoons by hunters has spread rapidly in the mid-Atlantic, moving to the north and east, and reaching Canada in 1999. ${ }^{27}$ This rapid spread is postulated to be due to the dense human population along the Eastern Seaboard, combined with raccoons in that region that were immunologically naïve to RRV. ${ }^{27}$ Increased human population density was postulated to increase raccoon populations by providing a preferred habitat in peridomestic settings, which could tend to result in animals being found in greater concentrations than might otherwise be expected. In contrast, western movement in WV appears to be slower, which may be due to lower raccoon densities or less suitable habitat. One hypothesis is that this may be due to the high ridges to the west acting as a physical barrier to raccoon (and virus) movement, ${ }^{28,29}$ although studies examining this hypothesis have been equivocal. ${ }^{30,31}$

To our knowledge, this is only the second ecological study to examine RRV in WV with an eye toward possible predictors, and clustering, of cases. The prior study indicated that rurality, as derived from the UIC, and percentage of agricultural land use were the only factors significantly predictive of RRV infection, with cases increasing as agricultural land use increased and as counties became less rural. ${ }^{36}$ That study did not account for spatial autocorrelation, however. That study also examined VA and North Carolina (NC), in addition to WV. This could explain the 
positive association with agriculture found in that study since, while WV is a predominantly rural state, it is not particularly agricultural, unlike VA and NC. Among the counties included in this study, only $0.8 \%$ of the total area available was used for agriculture, as compared to $27 \%$ (NC) and $32 \%(\mathrm{VA}){ }^{71,72}$ The low agricultural utilization in WV may have skewed our findings, as agricultural land use was not found to have an association with numbers of RRV cases.

Another potential issue with the prior study is that both VA and NC extend from the Appalachians to the Atlantic coast. Since the inadvertent introduction of RRV into the Middle Atlantic states, the disease has undergone rapid expansion from the original locus in the Appalachian Mountains, at times moving as rapidly as $30-60$ km per year. ${ }^{14}$ As a result, RRV has become well entrenched and enzootic throughout these states, and now extends into Canada. ${ }^{15}$ It is of note that while RRV has spread rapidly to the north and east from the original release site of the translocated animals, there has not been similar movement to the west. This may indicate that there are different predictor variables at play in the less mountainous non-Appalachian areas when compared to counties in Appalachia. West Virginia is the only state in the nation that is entirely contained within Appalachia, ${ }^{73}$ and as such, could present a rather unique situation with regard to RRV. The history of RRV movement since disease introduction would seem to indicate that there might be factors in WV preventing westward RRV movement that have yet to be delineated. The dramatic expansion of RRV to the east stands in rather stark contrast with the lack of westward movement of the virus, especially when one considers that the original release occurred on the WV - VA border nearly 40 years ago.

This study is limited by the available data as provided by the state Bureau of Public Health, insofar as cases were assigned to counties, rather than exact locations. This has a large impact on the elevation data points, because many of the study counties are at the westernmost edge of the 
Appalachian valley and ridge topography. Elevation for cases located in the valleys may be as much as 1000 feet lower than the mean county elevation, and can be up to 2000 feet lower than the highest point in those counties. An additional constraint inherent in this dataset is the inability to assess whether the animals submitted for testing are truly representative of the disease as it exists in the larger natural population of these hosts within the state. If a bias exists, it could easily result in an underestimation of the true impact of RRV. Additionally, the dataset provided only year of collection, so we were unable to assess any potential seasonality regarding RRV infection.

\section{Conclusion}

The clustering of RRV for each of the host types studied indicates that spatial factors are involved, and this tends to indicate that public health measures that target those counties included in the clusters are likely to have the greatest impact on reducing RRV cases. This study suggests that while there may be good support for believing that spatial factors have likely affected the westward movement of RRV in WV. However, based on limited available data, it is difficult to identify conclusively which factors are associated with RRV infection. Increased vaccination efforts by veterinarians and livestock owners in the counties within the clusters should directly reduce the pool of susceptible domestic animals. Likewise, elevated public awareness of the risk for RRV infection in both wildlife and domestic animals may be of value in reducing human exposure to the virus. Future directions for research efforts would include a spatiotemporal approach, which may elucidate the impact of spatial factors through time. Expansion of the study area to include those counties in states that share a border with WV would allow potential mitigation of the border effect. Another useful avenue for further investigation would evaluate the varying dynamics of RRV in disparate host types. 
Figure 2.1: Total number of raccoon variant rabies virus (RRV) infected animal captures at the county level in West Virginia, 2000-2015.

\section{Total RRV cases 2000-2015}

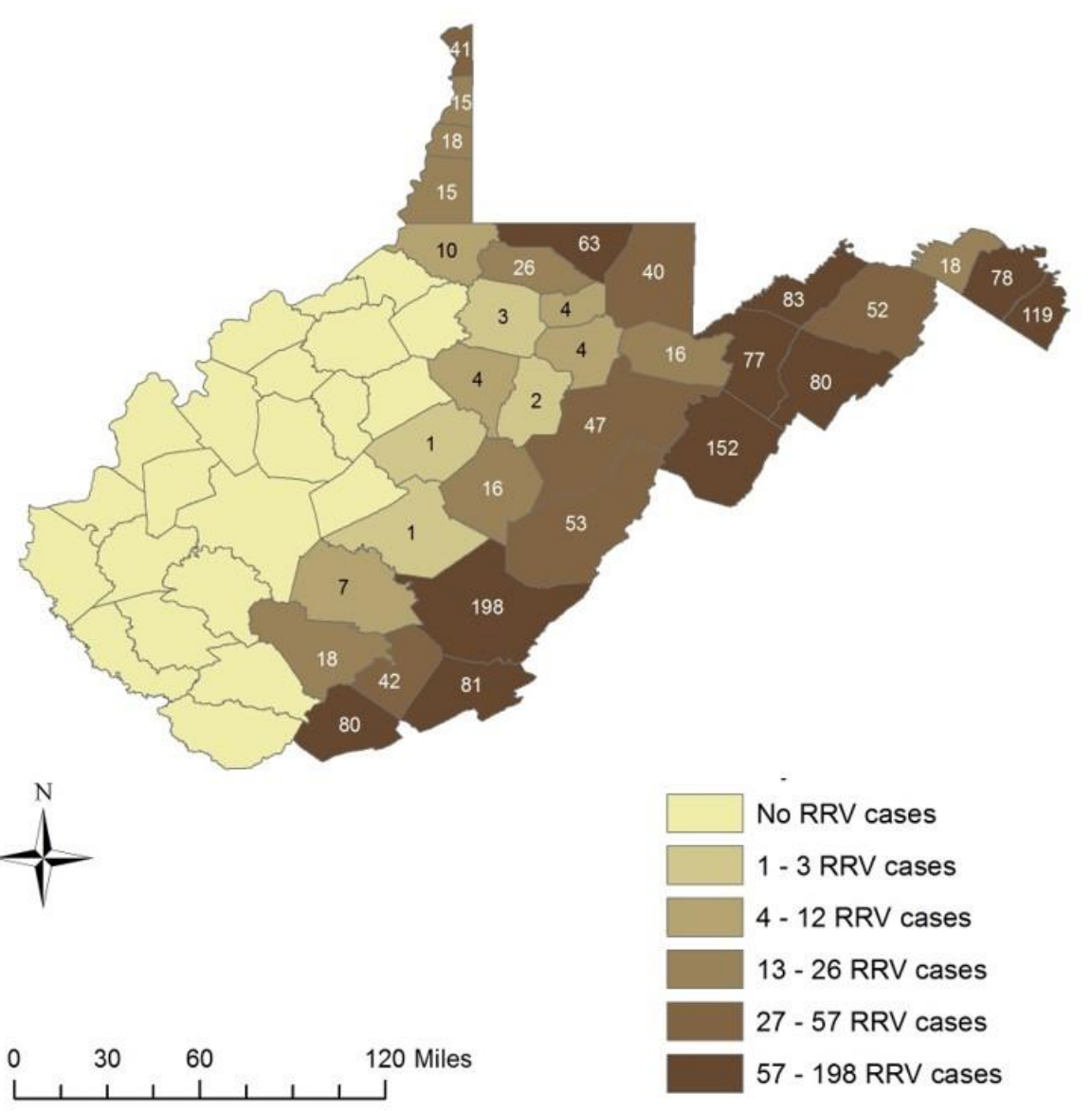


Figure 2.2: Local indicators of spatial autocorrelation maps for each of the host types examined, produced to investigate local clustering of raccoon variant rabies virus (RRV) at the county level in West Virginia, 2000-2015

Total RRV positives, $2000-2015$

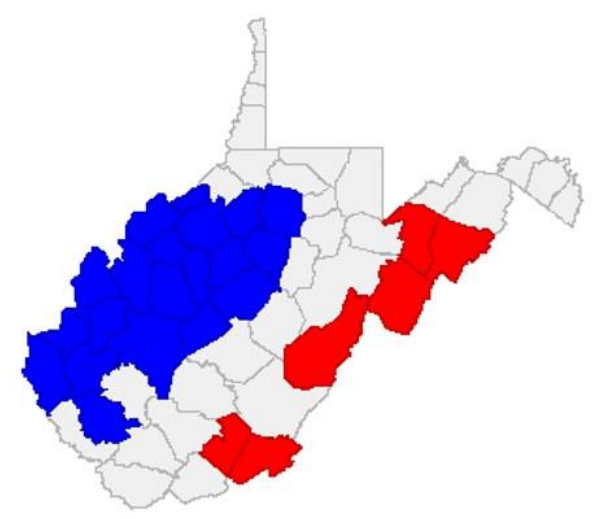

RRV positive NDNR, 2000-2015

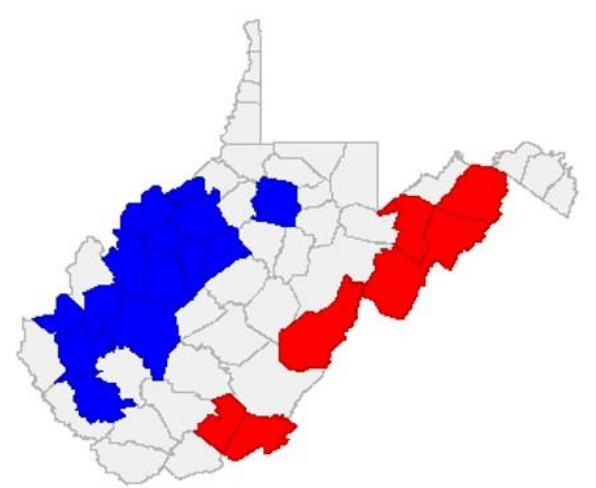

RRV positive raccoons, 2000-2015

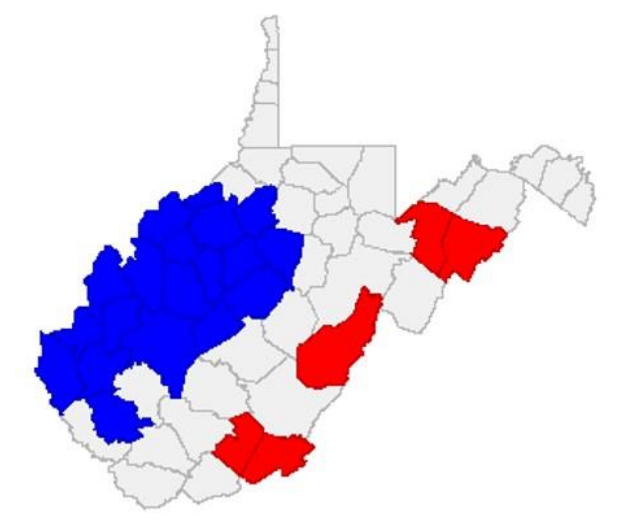

RRV positive domestic animals, 2000-2015

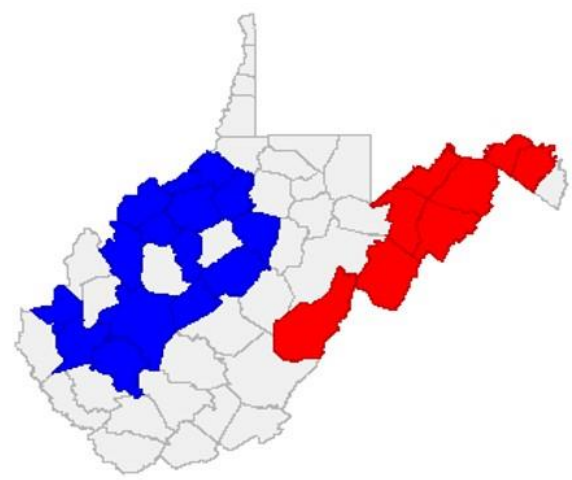

For each of these maps, red indicates clustered counties that have significantly $(\alpha=0.05)$ higher RRV case counts for the study period, while blue represents clustered counties with significantly lower case counts. 
Table 2.1: Variables found by univariate Poisson regression (using a log link function) to be significantly $(\alpha=0.05)$ associated with RRV infection by host type, West Virginia, 2000-2015. Values are reported as the median posterior ( $95 \%$ credible interval).

\begin{tabular}{|c|c|c|c|c|c|}
\hline Host type & $\begin{array}{l}\text { Mean elevation } \\
\text { (in 100 ft } \\
\text { increments) } \\
\end{array}$ & Area $\left(\mathbf{k m}^{2}\right)$ & \% Developed & \% Shrubland & VA Border? \\
\hline All Hosts & $\begin{array}{c}0.18 \\
(0.07,0.27)\end{array}$ & $\begin{array}{c}0.12 \\
(0.01,0.23)\end{array}$ & & $\begin{array}{c}4.61 \\
(0.001,10.19)\end{array}$ & $\begin{array}{c}1.84 \\
(0.37,3.20)\end{array}$ \\
\hline Raccoons & $\begin{array}{c}0.18 \\
(0.08,0.27) \\
\end{array}$ & $\begin{array}{c}0.13 \\
(0.04,0.22) \\
\end{array}$ & $\begin{array}{c}-0.19 \\
(-0.42,-0.02) \\
\end{array}$ & $\begin{array}{c}4.64 \\
(0.28,10.34) \\
\end{array}$ & $\begin{array}{c}1.60 \\
(0.28,3.00) \\
\end{array}$ \\
\hline $\mathbf{N D N R}^{1}$ & $\begin{array}{c}0.23 \\
(0.03,0.43) \\
\end{array}$ & & & & \\
\hline $\begin{array}{c}\text { Domestic } \\
\text { animals }\end{array}$ & $\begin{array}{c}0.17 \\
(0.07,0.29)\end{array}$ & $\begin{array}{c}0.17 \\
(0.07,0.29)\end{array}$ & $\begin{array}{c}-0.23 \\
(-0.42,-0.01)\end{array}$ & & $\begin{array}{c}1.99 \\
(0.69,3.23)\end{array}$ \\
\hline
\end{tabular}

${ }^{1} \mathrm{NDNR}=$ Non domestic, non-raccoon (all non-raccoon wildlife) 


\title{
CHAPTER THREE
}

\section{Exploratory Spatiotemporal Analysis of Raccoon Variant Rabies Virus Infection, West Virginia, 2000-2015}

\begin{abstract}
Raccoon variant rabies (RRV) infection has become enzootic in the Eastern United States after an accidental translocation of rabid raccoons by raccoon hunters in the late 1970 s. ${ }^{13}$ Given the rapid expansion of the virus to the east and north subsequent to this release, viral movement to the west into West Virginia has been surprisingly slow, especially considering the state's geographic proximity to the initial release site. The current study evaluates several spatial covariates as they change with time in order to determine whether there is an association with concurrent changes in RRV incidence. Annual data obtained from the West Virginia Bureau of Public Health for the period 2000-2015 were combined with data regarding geographic location, demographics and land use for the same period. Analyses incorporated Integrated Nested Laplace Approximations (INLA), a recently developed Bayesian modelling approach that allows the simultaneous use of county and time as random effects. These analyses were done for several types of viral hosts. Univariate analyses indicated that several variables were associated with RRV infection for each host type, with county centroid longitude and proximity to the Virginia border exhibiting positive association for all host types. Multivariate analyses found that border proximity and time exhibited positive associations for the all hosts and raccoon host types, and border proximity maintained a positive association for domestic animals as well. Time was negatively associated for each host type. This study provides information that may aid in prediction of future
\end{abstract}


RRV infections and/or outbreaks, as well as providing guidance for the allocation of public health resources.

\section{Introduction}

Bayesian hierarchical models with random effects are one of the most widely used methods in public health and disease mapping. These models are traditionally fitted using Markov Chain Monte Carlo sampling (MCMC) ${ }^{63}$ Due to the nature of the hierarchical models and random effects, the convergence of MCMC can be very slow and unpredictable, with some individual analyses requiring hours or days to complete. Recently, Integrated Nested Laplace Approximation (INLA) was developed as an alternative method to fit Bayesian hierarchical models. ${ }^{74}$ INLA has been shown to be equivalent to MCMC for parameter estimation, with substantially reduced computational burdens and improved analytic time requirements. ${ }^{75}$ Our prior studies examined determinants for RRV infection, either spatially or temporally, but neither considered the effects of space and time simultaneously due to the difficulty of implementation of MCMC methods to consider two random effects. In each of those studies, cases were aggregated by either time or space separately. In particular, our first study examined the changes in RRV cases over time, by aggregating the number of cases in each year, but ignoring the correlation of the data from county to county. ${ }^{20}$ The second study examined the total events from 2000-2015, taking into account the differences in spatial structure from county to county. This approach attempted to determine whether associations existed with the number of RRV cases in each county over the entire study period, but not longitudinally ${ }^{28}$ With the advent of INLA techniques, multiple random effects can be accommodated. The benefit of our models as implemented is threefold: (1) they include random effects, which allows them to handle more complicated data structures such as the correlation 
associated with repeated measurements for both space (county) and time (year); (2) they have the flexibility to assess effects of year and geospatial variables as covariates over time in the regression analysis; and (3) they do not suffer from the convergence problem due to small number of events and sample size (which is the most common issue in the MCMC approach).

The current study will use INLA methods to evaluate several possible geospatial determinants for RRV infection as both the determinants and case numbers change over time. It will examine whether temporal changes in those determinants are associated with changes in RRV infection incidence, and to identify which of these might act as predictors of RRV incidence, as well as assess whether temporal changes affect the utility of those predictor variables. Analyses were conducted for RRV infections in all hosts, as well as subpopulations of assorted viral hosts. These host subgroups are raccoons, nondomestic non-raccoons (NDNR) and domestic animals. The NDNR subgroup included all non-raccoon wildlife, such as foxes and skunks, which were found to be infected with RRV.

\section{Materials and Methods}

\section{Data collection and database structure}

Data related to rabies cases were obtained from the WV State Bureau of Public Health and consisted of annually reported rabies virus cases for RRV. The dataset used here is identical to that analyzed in the purely spatial study, excludes counties with no RRV cases in the study period, and incorporates the binary variables as previously described. 


\section{Analytic methods}

The data were combined to generate spatiotemporal regression models using INLA. By using a combination of analytic approximation and numerical integration, INLA avoids the convergence issues that arise with MCMC methods. Using INLA methods also permitted the simultaneous use of region (county) and time (year) as random effects variables within a Bayesian environment. As a result, the correlation inherent in a repeated measures analysis for both time (year) and space (county) is accounted for with all covariates. The statistical programming platform $\mathrm{R}$ (version 3.5.1) was used to evaluate the data, employing the INLA package (version 18.07.12). ${ }^{41,74}$

Given the count data examined, either Poisson or negative binomial regression approaches would have been appropriate. Exploratory examination of the data indicated that negative binomial regression was most appropriate, due to over-dispersion shown by the large variances as compared to the mean for each of the varying host types. The natural logarithm of county area (in $\mathrm{km}^{2}$ ) was used as the offset, as an offset term is suggested for negative binomial regression.

Both univariate and multivariate analyses were conducted, with the variables that exhibited associations in the univariate analyses used as a starting point for the multivariate models. To identify a final model, parsimonious models were created by removing variables whose credible interval included zero, with the variables having the least effect discarded first in a stepwise manner until only variables with credible intervals including zero remained. Time was evaluated as a fixed effect in the multivariate models, regardless of whether the credible interval bracketed zero, in addition to being used as a random effect. Each of the variables that had shown an association in the univariate analyses were evaluated for interactions. Continuous data were 
centered by subtracting the mean from each data value, and a 95\% credible interval was used as the association threshold for all analyses.

\section{Results}

There were a number of changes in the covariates over the study period, as shown in Table 3.1. In the counties that experienced at least one RRV case during the study period, human population and human population density increased by 6.1 and 4.13 percent respectively. Among the land use variables, the percentages of developed land, barren land and shrubland all increased by $5.3 \%, 28.66 \%$ and $1240.74 \%$ respectively. The relative amounts of forested land, agricultural land, and wetland all declined by $0.68 \%, 1.03 \%$ and $0.45 \%$ respectively. There was a net increase of three urban counties in the area studied, with four counties gaining urban status (Barbour, Brooke, Fayette, and Raleigh), while Morgan County changed from urban to rural.

A summary of the study's univariate regression findings is given in Table 3.2. For the evaluation of all hosts combined, human population, centroid longitude, percentage of county land devoted to agriculture and sharing a border with VA were all positively associated with RRV incidence (coefficients of $0.02,0.68,0.05$, and 1.79 respectively) after the software package adjusted for the effects of spatial autocorrelation and temporal changes in both the outcome and predictors. For example, this may be interpreted as indicating that for every 1000 person increase in a county's human population, one would anticipate that the number of RRV cases in all hosts would increase by approximately one $(\log 0.02)$. Similarly, a county on the VA border could be expected to have roughly six (log 1.79$)$ more all hosts cases than a county not on that border.

Each of the varying host subtypes were examined as well. Raccoons exhibited similar associations for all the variables that were positively associated with the combined group 
(coefficients of $0.02,0.53,0.05$, and 1.44, respectively). In addition, percentage of shrubland showed a positive association with RRV case numbers, while percentage of forested land use demonstrated negative association (coefficients of 1.32 and -0.03 respectively). A rather different pattern developed when the NDNR (all non-raccoon wildlife) host type was considered. Longitude and border proximity continued to show positive association $(1.04,2.72)$ with RRV case counts. Centroid latitude, percentage developed land use, and percentage wetland each showed a negative association (coefficients of $-0.94,-0.15$ and -0.57 respectively), while elevation showed a positive association (0.09). Similar to the situation described for all host and raccoon host types, centroid longitude, proximity to VA, and percentage agricultural land use showed positive association for domestic animals (respective coefficients of $0.97,1.84$ and 0.06). Percentage of barren land demonstrated negative association with RRV numbers (-1.02).

Multivariate analyses found that bordering VA was positively associated for most of the host types studied. With regard to the all hosts and raccoon models, proximity to the VA border was found to have a positive association (coefficients of 1.78 and 1.44 respectively), while time was found to have a negative effect for both models (coefficient of -0.03 for each). This indicates that, for two hypothetical counties identical in all other aspects, one located on the VA border would be expected to have approximately 5.9 more cases of RRV for all hosts than one not located on the border. Examination of the NDNR wildlife multivariate regression model revealed that longitude and latitude each displayed association, with longitude being positively associated and latitude negatively (coefficients of 1.93 and -1.90, respectively). An increase in longitude indicates eastward movement, while latitude decreases as one moves south. The final multivariate model for domestic animals contained both border proximity and longitude, with both having a positive effect (coefficients of 1.14 and 0.49 respectively). Time continued to have negative coefficients 
in each of these latter models, although the credible intervals did not contain zero. No interactions were noted between any of the variables retained in the final models.

\section{Discussion}

We undertook this study to determine whether geospatial and demographic variables might be associated with RRV cases as those variables and case numbers changed over time. Our earlier work indicated that there had been an overall decline in RRV numbers for the study period, but that decline did not extend to each of the host subtypes. ${ }^{66}$ Another of our studies demonstrated spatial clustering of RRV cases in WV, and identified several spatial covariates that exhibited significant associations with RRV incidence. ${ }^{76}$ The current study explores possible associations with RRV infections as case numbers and values for covariates varied over the study period. This was an exploratory analysis, and is intended to help generate hypotheses, as opposed to hypothesis testing.

There were changes over time in levels of the various covariates studied. The increase in developed land, along with decreases in forested and agricultural use, may be attributable to increases in human population and population density. This may also be the case for the reduction in wetlands. The dramatic increases in the barren, and especially shrubland, land use types may be more reflective of changes in satellite imaging technology rather than, or in addition to, true changes in land use. Several counties in the study area were reported with zero shrubland until the 2011 NLCD dataset, after which point shrubland was identified. It seems unlikely that these counties would have suddenly developed shrubland in the five-year period since the 2006 NLCD. These technological changes would presumably have affected other land use types as well, but the reporting in the 2001 and 2006 datasets may have tended to buffer the effect of the changes. 
Any associations found may be interpreted as indicating the effect of a given factor after adjusting for the effects of space (spatial autocorrelation) and time (temporal autocorrelation). Positive associations with longitude and proximity to the VA border were found for each host type with univariate modelling. This suggests that case counts increase as one proceeds east, as well as in those counties with proximity to VA. In addition, human population and percentage of agricultural land use had a positive association in the all host type, as well as in raccoons. The positive association with both human population and agricultural land use is consistent with the published literature, which indicates that raccoon numbers tend to increase around human habitations, and that the animals' preferred habitat is in forested areas adjacent to fields of agricultural crops. ${ }^{43,69,70}$ It seems reasonable to anticipate that an increase in the raccoon population could result in greater RRV case numbers, with an increase in risk of exposure for human populations. The finding that the covariates are similar for both the all host and raccoon groups is not surprising, since the bulk (66\%) of the animals in this study were raccoons. In addition to those covariates, the percentage of forested land showed a negative association with RRV infection when considered for raccoon hosts. The positive effect of shrubland is best interpreted with caution, given the difficulties regarding shrubland classification already discussed.

The values for NDNR wildlife stand in rather dramatic contrast to the other host types. While longitude and border proximity remain associated for this host type, latitude was negatively associated with RRV cases as well, indicating that cases in this host type tended to decrease as one moved south and increase with eastward movement through the state. The negative association of developed land, and concurrent increased contact with humans, in this host type seems to be consistent with typical behavior noted in these animals. 
The findings for domestic animals closely emulate those for all hosts and raccoons. Longitude and the VA border continue to be positively associated with RRV. The positive association with agricultural land use could reflect the number of livestock in the population, as they comprise $27 \%$ of the domestic animals in the study. Barren land showed a negative association, perhaps due to barren land not being conducive to agriculture.

Proximity to the VA border and longitude were the strongest predictors of RRV infection for each host type in the univariate regressions, and border proximity was included in most of the multivariate final models as well. Several of the associated values from the univariate analyses were removed in the final models, and retained variables tended to be factors that do not change over time. Our failure to identify more labile covariates, while disappointing, indicates a need for further study to identify determinants that may help to explain the changes in RRV incidence seen in WV.

The lack of an association for the VA border in the non-raccoon wildlife hosts is of note. This may be indicative of movement of RRV away from the border in these hosts and could be a harbinger of similar movement in the other host types for the future. However, the increase in RRV incidence as one moves eastward (increasing longitude) and southward (decreasing latitude) through the state may be serving to confound an association with border proximity that might otherwise be present in that host type, insofar as movement in either of those directions also tends to be in the direction of the VA border as well. Moreover, the small number of cases in the nonraccoon wildlife host type may have resulted in insufficient statistical power to allow the detection of such an association. The pattern of significance for time corroborates our previous findings, ${ }^{66}$ as RRV cases experienced a significant decline in the combined and raccoon only host types, but 
did not do so for wildlife or domestic animals. These findings precisely mirror the pattern seen in our earlier work.

To our knowledge, there had been only one ecological study of RRV in WV prior to our work. That study did not consider the effects of spatial autocorrelation however, nor any temporal effects on covariates and RRV case counts. The study did find that human agricultural land use and rurality each had a positive effect, resulting in increased risk of human exposure to a rabid raccoon. ${ }^{36}$ Other investigators have examined environmental and demographic factors postulated to affect raccoon numbers, and by extension RRV infections. One study found that human population density, surface water, residential land use, agriculture and industrial development each showed a significant positive association with RRV outbreaks, while both deciduous and mixed (deciduous and conifer) forestation reduced the odds of epizootic RRV. ${ }^{35}$ In the current study, however, none of these factors were shown to have an association with RRV case numbers once space and time were accounted for in the regression model simultaneously. The land use and demographic variables examined failed to show an association, with the immutable factor of border status having the strongest association with viral infections.

The more robust analytic approach provided by the INLA technique allowed for a more realistic examination of the data as both dependent and independent variables changed with time. Adjustment for both spatial and temporal autocorrelation permitted consideration of the various covariates without the statistical "noise" that would otherwise tend to muddy our results. It is of interest that INLA suggested covariates as significant that were found in each of our previous studies. ${ }^{66,76}$

Data constraints limited the study as conducted. The lack of precise locations of animal collection in the data provided by the state Bureau of Public Health prevented assignment of the 
exact existing conditions to each case. This forced us to use overall county level data as a proxy for more precise values. The necessary subdivision of the case counts by county and year for the analyses undoubtedly resulted in very small case counts in some instances, which would tend to affect the statistical power of the analyses negatively. It is impossible to assess whether the animals submitted for testing truly represent the disease as it exists in the larger natural population of the various hosts within the state. This is of particular concern with regard to the raccoon and NDNR hosts, as they would be more likely to have occult infections, in which the cases might easily die without being detected. Detection in domestic animals is more likely prior to their death, although that is certainly not the case universally. It seems nearly certain that the animals collected represent a biased sample of the population as a whole, resulting in an underestimation of the true impact of RRV. Finally, given that the dataset provided only county and year of collection, we were unable to assess any potential seasonality with regard to RRV infection dynamics.

\section{Conclusion}

With regard to the findings of this study, the strong association of border proximity with RRV incidence is of particular interest. Affected counties would be promising sites for the application of prevention measures. While prior studies have demonstrated that the oral rabies vaccine project of the USDA/APHIS Wildlife Services is effective, ${ }^{19,66}$ additional prevention and education efforts concentrated in border counties would seem warranted. Campaigns promoting rabies vaccination for domestic animals, including livestock, will presumably reduce the number of potentially susceptible animals in that population, as well as increasing public awareness regarding the risk of exposure from wildlife. The finding that case numbers are declining overall, as well as in raccoons, is encouraging. This is especially true for raccoons as they are the primary reservoir for RRV. Our inability to demonstrate an association for covariates that might pertain to 
habitat types, and selection, is of concern. Further investigation of the determinants for RRV infection in the varying host types would be of benefit in continuing to expand the knowledge base regarding this public health concern, as would evaluating additional covariates that might be associated with habitat. This is particularly important since we have been unable to demonstrate the commensurate decline in wildlife and domestic animal cases that one would anticipate with the decline in raccoon cases. Improved information regarding RRV incidence would be invaluable to guide planning for public health interventions, allocation of prevention resources and targeting of prevention efforts. 
Figure 3.1: Map of West Virginia showing those counties with at least one RRV case during the study period

\section{WV Counties with at least 1 RRV case, 2000-2015}

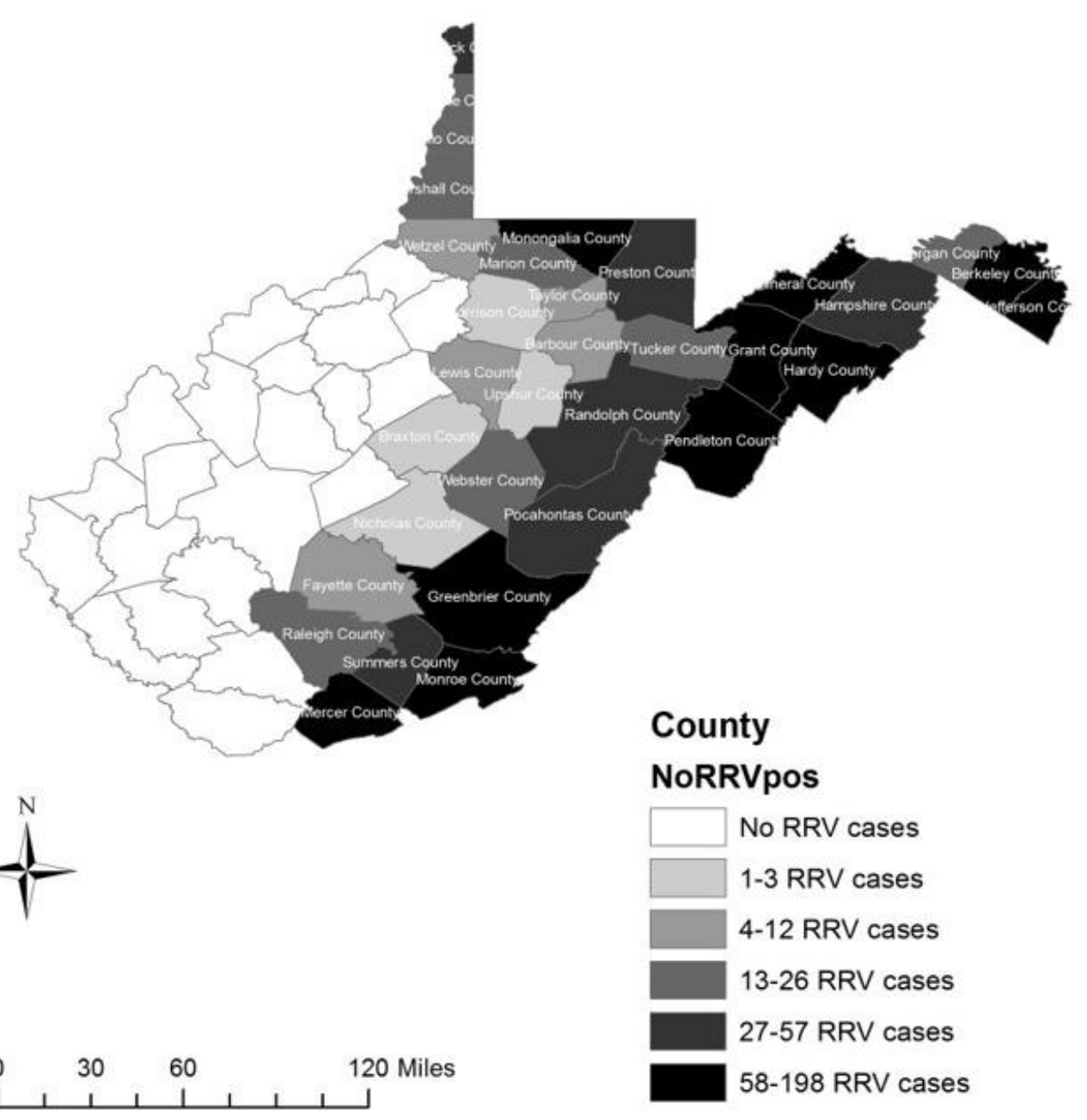


Table 3.1: Changes in value, among the WV counties with at least one RRV case, for the various covariates over the study period, 2000-2015.

Variable
Human Population
Human Population Density
$\%$ Developed
$\%$ Forested
$\%$ Agriculture
$\%$ Wetland
$\%$ Barren
$\%$ Shrubland

Percent change over study period

6.1

4.13

5.3

$-0.68$

$-1.03$

$-0.45$

28.66

1240.74 
Table 3.2: Variables examined by univariate INLA negative binomial regression (using a log link function) for association with RRV infection by host type, West Virginia, 2000-2015. Values are reported as the mean posterior (95\% credible interval). Apart from time, only variables whose $95 \%$ credible interval does not include zero are reported.

\begin{tabular}{|c|c|c|c|c|}
\hline \multirow{2}{*}{ Variable } & \multicolumn{4}{|c|}{ Host Type } \\
\hline & All Hosts & Raccoons & Non-raccoon Wildlife & Domestic Animals \\
\hline Human Population & & $0.02(0.002,0.04)$ & & $9.83(9.12,10.55)$ \\
\hline Latitude & & & $-0.94(-1.83,-0.09)$ & \\
\hline Longitude & $0.68(0.21,1.16)$ & $0.54(0.09,1.00)$ & $1.04(0.40,1.76)$ & $0.97(0.57,1.45)$ \\
\hline$\%$ Developed & & & $-0.16(-0.31,-0.02)$ & \\
\hline$\%$ Forested & & $-0.03(-0.07,-0.001)$ & & \\
\hline$\%$ Wetland & & & $-0.57(-1.10,-0.07)$ & \\
\hline$\% \mathrm{Ag}$ & $0.05(0.01,0.10)$ & $0.05(0.01,0.09)$ & & $0.08(0.02,0.42)$ \\
\hline$\%$ Barren & & & & $-0.98(-2.02,-0.02)$ \\
\hline$\%$ Shrubland & & $1.32(0.13,2.50)$ & & \\
\hline VA Border? & $1.75(0.99,2.53)$ & $1.41(0.64,2.21)$ & $2.72(1.78,3.78)$ & $1.85(1.07,2.77)$ \\
\hline Time (years) & $-0.03(-0.05,-0.01)$ & $-0.03(-0.05,-0.002)$ & $-0.02(-0.05,0.01)$ & $0.005(-0.05,0.06)$ \\
\hline
\end{tabular}


Table 3.3: Final models from results of multivariate INLA analyses performed using negative binomial regression (using a log link function) for association with RRV infection by host type, West Virginia, 2000-2015. Values are reported as the mean posterior (95\% credible interval(CI)).

\begin{tabular}{ccccc} 
Covariates & \multicolumn{2}{c}{ Host Type } \\
& All hosts & Raccoons & NDNR & Domestic \\
VA Border Proximity & 1.78 & 1.44 & & 1.14 \\
& $(1.00,2.56)$ & $(0.65,2.25)$ & & $(0.64,1.64)$ \\
Longitude & & & $(1.93$ & 0.49 \\
& & & -1.90 & \\
Latitude & & & $(-2.63,-1.22)$ & \\
Time (Years) & & & $-0.27,0.73)$ \\
& $(-0.06,-0.01)$ & $(-0.05,-0.002)$ & $(-0.05,0.01)$ & $(-0.05,0.05)$
\end{tabular}




\section{PROJECT CONCLUSIONS}

Rabies infections, and particularly those caused by the raccoon variant of the virus, have become a serious public health concern subsequent to the unintended release of rabid raccoons by hunters along the West Virginia - Virginia border in the late 1970s. ${ }^{13}$ Over the course of the four decades since that event, the disease has expanded dramatically. It currently extends eastward to the Atlantic coast and north into Canada. ${ }^{52}$ Curiously, there has not been similar westward viral movement. In fact, the furthest west the disease has extended in West Virginia is only approximately 100 miles west of that original release site. This project was designed to explore whether there are spatial factors that can help explain this notable lack of westward encroachment by the virus.

There have been relatively few studies published that have examined spatial characteristics

for association with raccoon variant rabies virus (RRV) infections in West Virginia, ${ }^{36,77}$ and none that have considered the autocorrelation inherent in spatial analyses. Together, results from the three studies presented here address gaps in knowledge regarding RRV behavior across time and space, as well as providing the initial description of the use of various autocorrelative approaches in Bayesian regression analyses. They illustrate the importance and utility of these approaches when evaluating the behavior of infectious diseases at the area level. Longitudinal evaluation by itself did not give a complete picture of the current state of the virus, and while a purely spatial analysis indicated that several determinants could have an association with RRV incidence, it could not address the effect of time within the model. Several of those determinants were eliminated from consideration when the random effects of both space and time were accounted for. 
The first study examined the longitudinal behavior of RRV, incorporating area (county) as a random effect. A significant reduction in case counts over time was found for all hosts as well as raccoons. These reductions were not present for non-raccoon wildlife or domestic animals, however. The initial study was complemented by our second study, which examined the impact of a number of spatial characteristics, including potential geographic and demographic determinants, on RRV incidence. Mean county elevation and a county's inclusion in the border with Virginia were found to be most consistently associated, with each having a positive effect on case numbers. Additionally, there were some indications that land use type might have an effect. The second study also identified clustering of high RRV incidence counties, with the majority of counties in those clusters being located on the Virginia border. These results from the second study show that while the disease continues to affect counties along the eastern border of the state, it continues to show no predilection for westward movement. Aggressive public health efforts in those counties have real potential for substantial impact on the virus.

The final study found that being a component of the Virginia border, as well as a relatively eastern location, served as the best predictors for RRV infection for most of the host types, and that there was a significant effect of time as a covariate for the all host and raccoon host types. This serves to corroborate the findings of the second study, as well as replicating those of the first.

It would appear that the INLA approach produces comparable results to those of the more traditional statistical techniques, while providing a more realistic model that accounts for multiple random effects yet is less computationally intensive. Additionally, a comparison of the three techniques shows that, in general, the coefficient values from the INLA approach tend to parallel those derived from the standard methods but are usually closer to zero relative to those prior 
techniques. (Figure 4.1) This makes sense, as it seems reasonable that incorporating two random effects would tend to buffer any of the effects found when considering those effects singly.

While it is somewhat disappointing that these studies failed to identify any significant factors associated with RRV incidence that are amenable to modification, when taken as a whole there is a strong indication that, while RRV case numbers are declining for all hosts combined as well as raccoon hosts, the effect is limited to those host types regardless of the analytic technique employed. The decline noted is at least partially due the ORV program, and could also indicate that that the disease is beginning to "burn itself out." Another finding that may be of use is the counties with higher incidence numbers cluster in the east of the state along the Virginia border.

Armed with these results, a strong argument can be made that preferential allocation of prevention efforts and resources to those heavily affected counties is warranted. Resource allocation to the counties along the VA border could include an aggressive campaign to increase rabies vaccination rates in all domestic animals, as well as a program to develop and increase public awareness of this potentially fatal threat. While the oral rabies vaccination program was shown to have a beneficial effect, it by itself cannot adequately explain the failure of the virus to move west through the state, since there had not been such movement in the nearly twenty-year period before the program began. Nonetheless, given the success of the program, eastward expansion of the vaccine distribution zone would likely have a favorable result. Increased vaccine availability, along with expanded oral vaccine distribution, could be the steps necessary to begin to shift RRV eastward.

Future directions to be considered should include further work to identify other spatial variables that might impact RRV incidence. Another approach that could be useful would be to expand the study area beyond West Virginia while restricting it to Appalachia. This would increase 
sample size, thereby improving statistical power. It would also avoid the potential confounding effect of aggregating counties that do not share similar characteristics, as found in a previous study. ${ }^{36}$ 


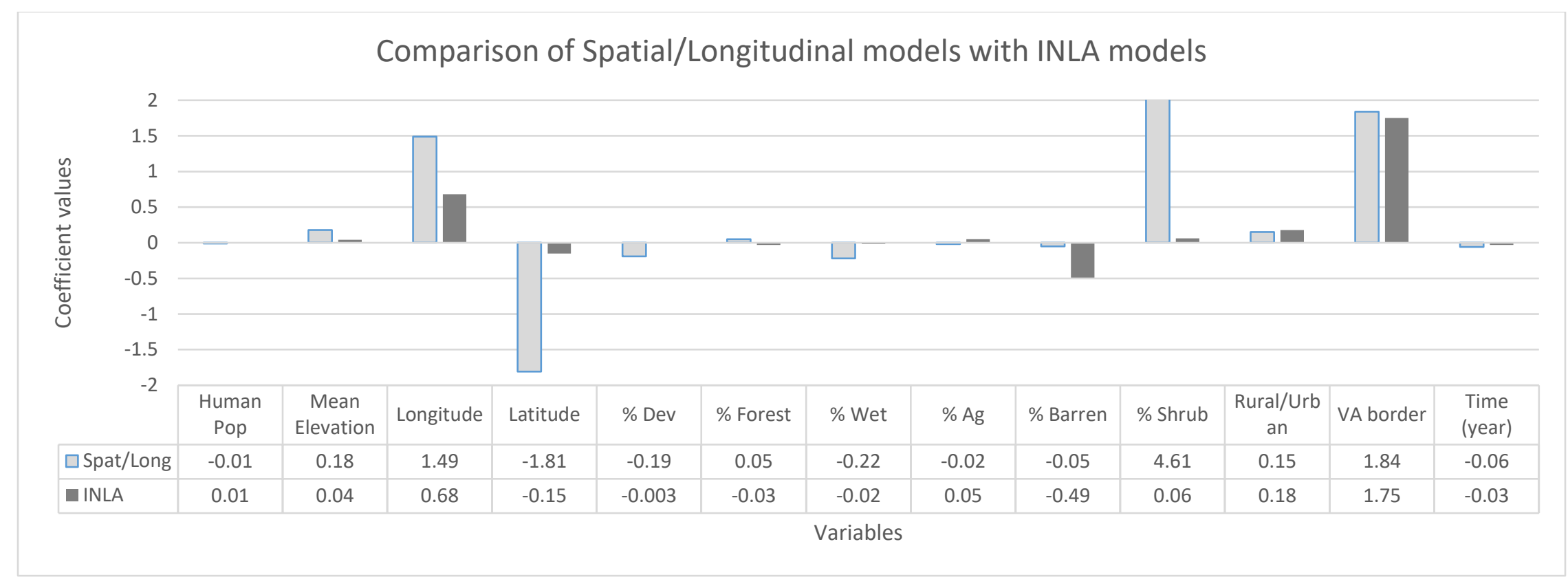

Figure 4.1: This chart allows comparison of the modelling techniques used in this project. Note that, in general, the INLA approach resulted in coefficients that were closer to zero than either the spatial or longitudinal models. The longitudinal model aggregated RRV incidence data without regard to spatial autocorrelation, while the spatial models aggregated the data without regard to temporal correlation. The INLA model adjusted for the correlation of both time and space simultaneously. Please note that while the data presented here apply to the all hosts model, similar results were obtained for the various host types. Because this figure is presented for use in comparing the techniques, data are provided without regard to whether the $95 \%$ credible interval included zero. 


\section{LITERATURE CITED}

1. Adamson PB. The spread of rabies into Europe and the probable origin of this disease in antiquity. Journal of the Royal Asiatic Society of Great Britain \& Ireland Royal Asiatic Society of Great Britain and Ireland. 1977;2:140-144.

2. $\quad$ Prevention CfDCa. Etymologia: Rabies. Emerging Infectious Diseases. 2012;18(7):1169.

3. Velasco-Villa A, Mauldin MR, Shi M, et al. The history of rabies in the Western Hemisphere. Antiviral Research.

4. Prevention CfDCa. CDC - Rabies in the US - Rabies. https://www.cdc.gov/rabies/location/usa/index.html. Accessed 21 April, 2017.

5. Rabies - Wikipedia. 2017; https://en.wikipedia.org/wiki/Rabies.

6. Lozano R, Naghavi M, Foreman K, et al. Global and regional mortality from 235 causes of death for 20 age groups in 1990 and 2010: a systematic analysis for the Global Burden of Disease Study 2010. Lancet. 2012;380(9859):2095-2128.

7. Willoughby RE, Jr., Tieves KS, Hoffman GM, et al. Survival after treatment of rabies with induction of coma. The New England journal of medicine. 2005;352(24):2508-2514.

8. Chipman RB, Cozzens TW, Shwiff SA, et al. Costs of raccoon rabies incidents in cattle herds in Hampshire County, West Virginia, and Guernsey County, Ohio. J Am Vet Med Assoc. 2013;243(11):1561-1567.

9. Slate D, Chipman RB, Rupprecht CE, DeLiberto T. Oral Rabies Vaccination: A National Perspective on Program Development and Implementation. 2002.

10. Slate D, Rupprecht CE, Rooney JA, Donovan D, Lein DH, Chipman RB. Status of oral rabies vaccination in wild carnivores in the United States. Virus research. 2005;111(1):68-76.

11. United States Department of Agriculture AaPHIS. USDA - APHIS | West Virginia ORV Distribution Data. 2014;

https://www.aphis.usda.gov/aphis/ourfocus/wildlifedamage/programs/nrmp/sa_informati on_by_state/ct_west_virginia_orv_distribution_data. Accessed 14 April, 2017.

12. Slate D, Chipman RB, Algeo TP, et al. Safety and immunogenicity of Ontario Rabies Vaccine Bait (ONRAB) in the first us field trial in raccoons (Procyon lotor). J Wildl Dis. 2014;50(3):582-595.

13. Nettles VF, Shaddock JH, Sikes RK, Reyes CR. Rabies in translocated raccoons. Am J Public Health. 1979;69(6):601-602.

14. Sterner RT, Meltzer MI, Shwiff SA, Slate D. Tactics and economics of wildlife oral rabies vaccination, Canada and the United States. Emerg Infect Dis. 2009;15(8):11761184.

15. Wallace RM, Gilbert A, Slate D, et al. Right place, wrong species: a 20-year review of rabies virus cross species transmission among terrestrial mammals in the United States. PloS one. 2014;9(10):e107539.

16. West Virginia Department of Health and Human Services BoPH. Archived Rabies Surveillance Data. 2017; http://www.dhhr.wv.gov/oeps/disease/Zoonosis/Rabies/Documents/Rabies_by_County.p df. Accessed 1 March, 2017.

17. Legislature W. West Virginia Code 19-20A-2. 2017.

18. Rupprecht CE, Hanlon CA, Slate D. Control and prevention of rabies in animals: paradigm shifts. Developments in biologicals. 2006;125:103-111. 
19. Ma X, Blanton JD, Rathbun SL, Recuenco S, Rupprecht CE. Time series analysis of the impact of oral vaccination on raccoon rabies in West Virginia, 1990-2007. Vector borne and zoonotic diseases (Larchmont, NY). 2010;10(8):801-809.

20. One Health Initiative - One World One Medicine One Health. 2017; http://www.onehealthinitiative.com/.

21. Dyer JL, Wallace R, Orciari L, Hightower D, Yager P, Blanton JD. Rabies surveillance in the United States during 2012. J Am Vet Med Assoc. 2013;243(6):805-815.

22. Dyer JL, Yager P, Orciari L, et al. Rabies surveillance in the United States during 2013. $J$ Am Vet Med Assoc. 2014;245(10):1111-1123.

23. Monroe BP, Yager P, Blanton J, et al. Rabies surveillance in the United States during 2014. J Am Vet Med Assoc. 2016;248(7):777-788.

24. Dellicour S, Rose R, Pybus OG. Explaining the geographic spread of emerging epidemics: a framework for comparing viral phylogenies and environmental landscape data. BMC bioinformatics. 2016;17:82.

25. Hubbard DR. A descriptive epidemiological study of raccoon rabies in a rural environment. J Wildl Dis. 1985;21(2):105-110.

26. Guerra MA, Curns AT, Rupprecht CE, Hanlon CA, Krebs JW, Childs JE. Skunk and raccoon rabies in the eastern United States: temporal and spatial analysis. Emerg Infect Dis. 2003;9(9):1143-1150.

27. Childs JE, Curns AT, Dey ME, Real AL, Rupprecht CE, Krebs JW. Rabies epizootics among raccoons vary along a North-South gradient in the Eastern United States. Vector borne and zoonotic diseases (Larchmont, NY). 2001;1(4):253-267.

28. Moore DA. Spatial diffusion of raccoon rabies in Pennsylvania, USA. Prev Vet Med. 1999;40(1):19-32.

29. Szanto AG, Nadin-Davis SA, Rosatte RC, White BN. Genetic tracking of the raccoon variant of rabies virus in eastern North America. Epidemics. 2011;3(2):76-87.

30. Root JJ, Puskas RB, Fischer JW, et al. Landscape genetics of raccoons (Procyon lotor) associated with ridges and valleys of Pennsylvania: implications for oral rabies vaccination programs. Vector borne and zoonotic diseases (Larchmont, NY). 2009;9(6):583-588.

31. Puskas RB, Fischer JW, Swope CB, Dunbar MR, McLean RG, Root JJ. Raccoon (Procyon lotor) movements and dispersal associated with ridges and valleys of Pennsylvania: implications for rabies management. Vector borne and zoonotic diseases (Larchmont, NY). 2010;10(10):1043-1048.

32. Smith DL, Lucey B, Waller LA, Childs JE, Real LA. Predicting the spatial dynamics of rabies epidemics on heterogeneous landscapes. Proceedings of the National Academy of Sciences of the United States of America. 2002;99(6):3668-3672.

33. Lucey BT, Russell CA, Smith D, et al. Spatiotemporal analysis of epizootic raccoon rabies propagation in Connecticut, 1991-1995. Vector borne and zoonotic diseases (Larchmont, NY). 2002;2(2):77-86.

34. Smith DL, Waller LA, Russell CA, Childs JE, Real LA. Assessing the role of longdistance translocation and spatial heterogeneity in the raccoon rabies epidemic in Connecticut. Prev Vet Med. 2005;71(3-4):225-240.

35. Jones ME, Curns AT, Krebs JW, Childs JE. Environmental and human demographic features associated with epizootic raccoon rabies in Maryland, Pennsylvania, and Virginia. J Wildl Dis. 2003;39(4):869-874. 
36. Reilly S, Sanderson WT, Christian WJ, Browning SR. Geographical Clusters and Predictors of Rabies in Three Southeastern States. Vector borne and zoonotic diseases (Larchmont, NY). 2017.

37. Services OoL. OLS - Rabies. 2018; http://www.wvdhhr.org/labservices/labs/rabies/index.cfm.

38. McQuiston JH, Yager PA, Smith JS, Rupprecht CE. Epidemiologic characteristics of rabies virus variants in dogs and cats in the United States, 1999. Journal of the American Veterinary Medical Association. 2001;218(12):1939-1942.

39. Bureau USC. Population and Housing Unit Estimates Datasets. https://www.census.gov/programs-surveys/ popest /data/data-sets.2000.html. Accessed 24 April, 2017.

40. Interior USDot. Multi-Resolution Land Characteristics Consortium. https://www.mrlc.gov/finddata.php. Accessed 12 April, 2017.

41. $R:$ A Language and Environment for Statistical Computing [computer program]. Version 3.4.1: R Foundation for Statistical Computing; 2017.

42. Generalized Linear Mixed Models using 'AD Model Builder' [computer program]. Version R package version 0.8.3.32016.

43. Erb PL, McShea WJ, Guralnick RP, Fenton B. Anthropogenic Influences on MacroLevel Mammal Occupancy in the Appalachian Trail Corridor. PloS one. 2012;7(8):1-10.

44. Chipman R. 2017.

45. Childs JE, Colby L, Krebs JW, et al. Surveillance and spatiotemporal associations of rabies in rodents and lagomorphs in the United States, 1985-1994. J Wildl Dis. 1997;33(1):20-27.

46. Gordon ER, Curns AT, Krebs JW, Rupprecht CE, Real LA, Childs JE. Temporal dynamics of rabies in a wildlife host and the risk of cross-species transmission. Epidemiol Infect. 2004;132(3):515-524.

47. Gordon ER, Krebs JW, Rupprecht CR, Real LA, Childs JE. Persistence of elevated rabies prevention costs following post-epizootic declines in rates of rabies among raccoons (Procyon lotor). Prev Vet Med. 2005;68(2-4):195-222.

48. Childs JE, Curns AT, Dey ME, et al. Predicting the local dynamics of epizootic rabies among raccoons in the United States. Proceedings of the National Academy of Sciences of the United States of America. 2000;97(25):13666-13671.

49. Rosatte R, Sobey K, Donovan D, et al. Behavior, movements, and demographics of rabid raccoons in Ontario, Canada: management implications. J Wildl Dis. 2006;42(3):589605.

50. Rupprecht CE, Hanlon CA, Hemachudha T. Rabies re-examined. The Lancet Infectious diseases. 2002;2(6):327-343.

51. Nelson K. National Rabies Management Program Summary Report 2010. 2010; http://www.aphis.usda.gov/wildlife_damage/oral_rabies/downloads/NationalReport_201 0.pdf, 2017.

52. Slate D, Algeo TP, Nelson KM, et al. Oral Rabies Vaccination in North America: Opportunities, Complexities, and Challenges. PLoS neglected tropical diseases. 2009;3(12):e549.

53. Survey USG. GNIS Feature Search. https://geonames.usgs.gov/apex/f?p=138:1:0 :::::. Accessed 5 May, 2017. 
54. Center WVGT. WVGISTC: GIS Data Clearinghouse.

http://wvgis.wvu.edu/data/dataset.php?ID=29. Accessed 26 April, 2017.

55. Agriculture USDo. USDA ERS - Urban Influence Codes. 2013; https://www.ers.usda.gov/data-products/urban-influence-codes/. Accessed 27 April, 2017.

56. Anselin L, Syabri I, Kho Y. GeoDa: An Introduction to Spatial Data Analysis. Geographical Analysis. 2006;38(1):5-22.

57. Li H, Calder Catherine A, Cressie N. Beyond Moran's I: Testing for Spatial Dependence Based on the Spatial Autoregressive Model. Geographical Analysis. 2007;39(4):357-375.

58. Moran PAP. Notes on Continuous Stochastic Phenomena. Biometrika. 1950;37(1/2):1723.

59. Lee D. CARBayes: An R Package for Bayesian Spatial Modeling with Conditional Autoregressive Priors. Journal of Statistical Software. 2013;55(13):1-24.

60. De Oliveira V. Bayesian Analysis of Conditional Autoregressive Models. Vol 64. 1 ed2012:107-133.

61. Lee D. A comparison of conditional autoregressive models used in Bayesian disease mapping. Spatial and spatio-temporal epidemiology. 2011;2(2):79-89.

62. Mohebbi M, Wolfe R, Forbes A. Disease Mapping and Regression with Count Data in the Presence of Overdispersion and Spatial Autocorrelation: A Bayesian Model Averaging Approach. International Journal of Environmental Research and Public Health. 2014;11(1):883-902.

63. Best N, Richardson S, Thomson A. A comparison of Bayesian spatial models for disease mapping. Statistical methods in medical research. 2005;14(1):35-59.

64. Lawson AB, Biggeri AB, Boehning D, et al. Disease mapping models: an empirical evaluation. Disease Mapping Collaborative Group. Statistics in medicine. 2000;19(1718):2217-2241.

65. Wakefield J. Disease mapping and spatial regression with count data. Biostatistics. 2006;8(2):158-183.

66. Plants KB, Wen S, Wimsatt J, Knox S. Longitudinal analysis of raccoon rabies in West Virginia, 2000-2015: a preliminary investigation. PeerJ. 2018;6:e4574.

67. Dreassi E, Biggeri A. Edge effect in disease mapping. Journal of the Italian Statistical Society. 1998;7(3):267.

68. Vidal Rodeiro CL, Lawson AB. An evaluation of the edge effects in disease map modelling. Computational Statistics \& Data Analysis. 2005;49(1):45-62.

69. Beasley JC, Devault TL, Retamosa MI, Rhodes OE. A Hierarchical Analysis of Habitat Selection by Raccoons in Northern Indiana. Journal of Wildlife Management. 2007;71(4):1125-1133.

70. Bozek CK, Prange S, Gehrt SD. The influence of anthropogenic resources on multi-scale habitat selection by raccoons. Urban Ecosystems. 2007;10(4):413-425.

71. Services NCDoAaC. https://www.ncleg.net/documentsites/committees/senate201366/Meetings/02-26-2013/2013-0226\%20D.Smith-NCDACS\%20Presentation.pdf, 2018.

72. Services VDoAaC. Agriculture Facts and Figures. 2018; http://www.vdacs.virginia.gov/markets-and-finance-agriculture-facts-and-figures.shtml, 2018. 
73. Commission AR. The Appalachian Region - Appalachian Regional Commission. 2018; https://www.arc.gov/appalachian_region/TheAppalachianRegion.asp. Accessed March 26, 2018.

74. Rue H, Martino S, Chopin N. Approximate Bayesian inference for latent Gaussian models by using integrated nested Laplace approximations. Journal of the Royal Statistical Society. 2009;71(2):319-392.

75. De Smedt T, Simons K, Van Nieuwenhuyse A, Molenberghs G. Comparing MCMC and INLA for disease mapping with Bayesian hierarchical models. Archives of Public Health. 2015;73(Suppl 1):O2-O2.

76. Plants KB, Wen S, Wimsatt J, Knox S. Exploratory Spatial Analysis of Raccoon Rabies in West Virginia, 2000-2015. West Virginia University; 2018.

77. Recuenco S, Eidson M, Kulldorff M, Johnson G, Cherry B. Spatial and temporal patterns of enzootic raccoon rabies adjusted for multiple covariates. International journal of health geographics. 2007;6:14. 